16

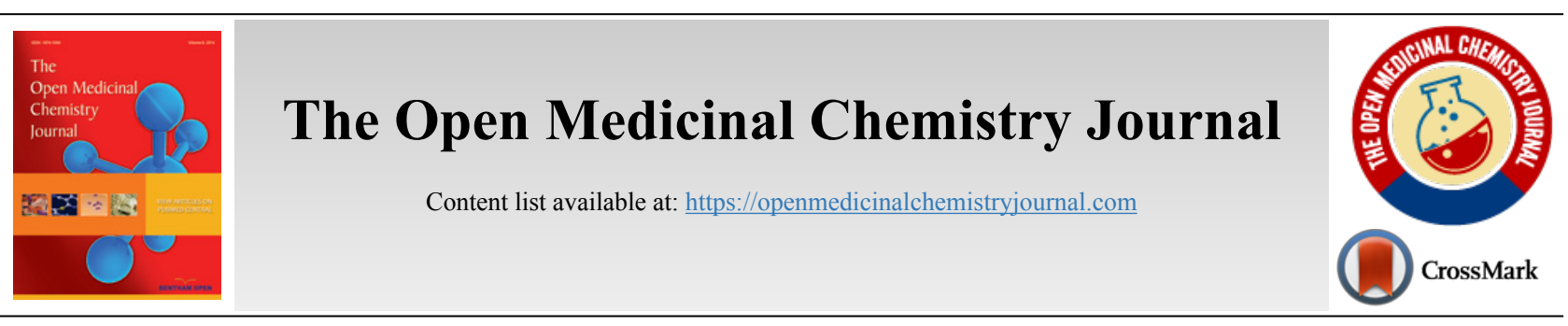

RESEARCH ARTICLE

\title{
Design and Synthesis of WM5 Analogues as HIV-1 TAR RNA Binders
}

Jenny Desantis ${ }^{1,2}$, Serena Massari ${ }^{1{ }^{*}}$, Alice Sosic ${ }^{3}$, Giuseppe Manfroni ${ }^{1}$, Rolando Cannalire ${ }^{1}$, Tommaso Felicetti ${ }^{1}$, Christophe Pannecouque ${ }^{4}$, Barbara Gatto ${ }^{3}$ and Oriana Tabarrini ${ }^{1}$

${ }^{\prime}$ Department of Pharmaceutical Sciences, University of Perugia, 06123 Perugia, Italy

${ }^{2}$ Department of Chemistry, Biology and Biotechnology, University of Perugia, 06123 Perugia, Italy

${ }^{3}$ Department of Pharmaceutical and Pharmacological Sciences, University of Padova, 35131, Padova, Italy

${ }^{4}$ Rega Institute for Medical Research, Laboratory of Virology and Chemotherapy, K.U. Leuven, K.U. Leuven, B-3000 Leuven, Belgium

\begin{abstract}
:
Background:

The 6-aminoquinolone WM5, previously identified by us, is among the most selective small molecules known as TAR RNA binders to show antiHIV activity.
\end{abstract}

Methods:

Starting from WM5, a series of analogues modified at N-1, C-6 or C-7 position was prepared by inserting guanidine or amidine groups as well as other protonable moieties intended to electrostatically bind the phosphate backbone of TAR. All the compounds were tested for their ability to inhibit HIV-1 replication in MT-4 cells and in parallel for their cytotoxicity. The active compounds were also evaluated for their ability to interfere with the formation of the Tat-TAR complex using a Fluorescence Quenching Assay (FQA).

Results:

Some of the synthesized compounds showed an anti-HIV-1 activity in the sub-micromolar range with the naphthyridone derivatives being the most potent. Three of the synthesized derivatives were able to interact with the Tat-TAR complex formation presenting Ki values improved as compared to the values obtained with WM5.

Conclusion:

The addition of a pyridine-based protonable side chain at the N-1 position of the quinolone/naphthyridone core imparted to the compounds the ability to interfere with Tat-TAR complex formation and HIV-1 replication.

Keywords: Anti-HIV quinolones, Tat-mediated transcription inhibitors, Antiviral agents, Medicinal chemistry, WM5, Fluorescence quenching assay.

Article History

Received: November 5, 2018

Revised: January 26, 2019

Accepted: February 5, 2019

\section{INTRODUCTION}

In the past decades, considerable work has been done in exploiting small non-coding hairpin RNA fragments as drug targets. However, compared with the compounds targeting proteins, the identification of molecules that selectively bind to structured RNA motifs remains an important challenge [1 - 3]. One of the most studied RNA structures is the Transactivation response element (TAR) of HIV-1 genome [4 - 9], a short stem-bulge-loop structure located in the long terminal repeat

\footnotetext{
* Address correspondence to this author at the Department of Pharmaceutical Sciences, University of Perugia, Via del Liceo 1, 06123, Perugia, Italy; Tel: +390755855134; E-mail: serena.massari@unipg.it
}

region at the 5' end of all nascent HIV-1 transcripts. Its specific interaction with the HIV-1 regulatory protein Tat is essential for viral gene expression, replication and pathogenesis $[10,11]$.

TAR RNA is extremely conserved among viral isolates making it a very attractive target. During the last two decades, many small molecules, aminoglycosides-conjugates, Tat-based peptidomimetics, and peptides have been reported as TAR binders [12 - 19].

Among the small molecules known as TAR RNA binder, the 6-aminoquinolone WM5 Fig. (1), which was developed in our lab, inhibits the Tat-mediated transactivation by interfering selectively with the bulge region of TAR RNA [20]. 
Numerous derivatives have been designed and synthesized starting from WM5 with the aim to gain Structure-Activity Relationship (SAR) insights, reduce the cytotoxicity and further investigate the molecular mechanism of action [21]. As a consequence, many compounds endowed with good HIV-1 and HIV-2 inhibitory activity in both chronically infected and acutely infected cells have already been identified. However, a direct correlation between the anti-HIV activity and their ability to interfere with the Tat-TAR RNA complex was not always observed [22]. On the other hand, when the quinolone nucleus lacking both C-7 arylpiperazine and C-3 carboxylic functions was properly functionalized with protonable groups at the C-2 position, a series of 2-phenylquinolones was obtained showing an improved ability to displace Tat-TAR complex but at the expense of antiviral activity [23, 24].

Here, we came back to WM5 preparing a series of analogues designed to enhance its ability to recognize the viral nucleic acid TAR RNA. Considering that TAR plays its essential role in the Tat-mediated transcription by specifically binding Tat and that in the Tat-TAR complex the arginine rich basic portion of Tat is responsible for the TAR binding, we decided to modify WM5 by inserting guanidine or amidine groups as well as other protonable moieties intended to bind electrostatically the phosphate backbone of TAR. In the present paper, the synthesis of a series of WM5 analogues modified at N-1, C-6 or C-7 position Fig. (1), and their anti-HIV-1 activity along with their cytotoxicity in MT-4 cells, are reported. The active compounds were also evaluated in a Fluorescence Quenching Assay (FQA) to determine their ability to interfere with the formation of the complex between TAR RNA and a truncated Tat peptide.

\subsection{Design of WM5 Analogues}

Starting from WM5, the C-6 amino group was replaced by a more basic guanidine in compound $\mathbf{1}$, while at $\mathrm{C}-7$ position an amidine moiety replaced the 2-pyridine ring in compound $\mathbf{2}$, and an imidazoline ring was present at the $\mathrm{C}-4$ position of the pyridine in compound 3 Fig. (1). Pyridine and (pyridinyl)piperazine moieties were inserted at the $\mathrm{N}-1$ position through methyl, ethyl, or propyl chains, as in compounds 4, 5 [25] and 6, respectively Fig. (1). Moreover, by maintaining the propyl chain, the piperazine and the pyridine rings were alternatively deleted as in compounds $\mathbf{7}$ and $\mathbf{8}$, respectively Fig. (1). We have previously reported that the 1,8-naphthyridone nucleus, when decorated with a 1,3-benzothiazolpiperazine moiety at the C-7 position, grants potent and selective anti-HIV activity $[26,27]$. Thus, the same flexible protonable side chains were also inserted at $\mathrm{N}-1$ position of the 1,8-naphthyridone scaffold, obtaining compounds 9 [25], 10 [25], 11, and 12 Fig. (1).

\section{MATERIALS AND METHODS}

\subsection{Chemistry}

Starting materials, reagents, and solvents that were commercially available were used as supplied. The reactions were monitored by TLC on silica gel 60F254 (Merck) and the compounds were visualized by UV and/or iodine. Flash chromatography columns were performed on Merck silica gel 60 (mesh 230-400). After extraction, organic solutions were dried using anhydrous $\mathrm{Na}_{2} \mathrm{SO}_{4}$, filtered, and evaporated to dryness at reduced pressure using a Büchi rotary evaporator. Yields are of pure products and were not optimized. Melting points were determined in capillary tubes (Büchi Electrothermal Mod. 9100) and are uncorrected. Elemental analyses were performed on a Fisons elemental analyzer, Model EA1108CHN, and the data for $\mathrm{C}, \mathrm{H}$ and $\mathrm{N}$ are within $\pm 0.4 \%$ of the theoretical values. ${ }^{1} \mathrm{H}$ NMR and ${ }^{13} \mathrm{C}$ NMR spectra were recorded at $200 \mathrm{MHz}$ (Bruker Avance DPX-200) and $400 \mathrm{MHz}$ (Bruker Avance DRX-400) using residual solvents such as dimethylsulfoxide $(\delta=2.48)$ or chloroform $(\delta=7.26)$ as an internal standard. Chemical shifts $(\delta)$ are reported in parts per million (ppm), and peak multiplicity are reported as s (singlet), $\mathrm{d}$ (doublet), $\mathrm{t}$ (triplet), q (quartet), p (pentet), hept (heptet), $\mathrm{m}$ (multiplet), or brs (broad singlet). Target compounds 5 [25], 9 [26], 10 [27] have been synthesized as previously reported.

\subsubsection{6-(E)-(2,3-Di-Tert-Butoxyguanidino)-1-Methyl-4-Oxo- 7-[4-(Pyridin2-yl)Piperazin-1-yl]]-1,4-Dihydroquinoline-3- Carboxylic Acid (13)}

To a solution of WM5 [20] $(0.13 \mathrm{~g}, 3.29 \mathrm{mmol})$ in dry DMF $(10 \mathrm{~mL}), \mathrm{Et}_{3} \mathrm{~N}(0.07 \mathrm{~g}, 7.24 \mathrm{mmol}, 0.1 \mathrm{~mL}), N, N^{\prime}$-di-(tertbutoxycarbonyl)thiourea $(0.10 \mathrm{~g}, 3.45 \mathrm{mmol})$, and $\mathrm{HgCl}_{2}$ (cat. amount) were added. The mixture was reacted at room temperature for $15 \mathrm{~min}$. The solvent was subsequently concentrated under vacuum and the residue was treated with $\mathrm{EtOH}$ yielding a precipitate that was eliminated by filtration. The filtrate was evaporated to dryness obtaining a solid that was washed with hot EtOH (3 times), filtered off, and dried to give compound $13(0.10 \mathrm{~g}, 10 \%): \mathrm{mp}>300{ }^{\circ} \mathrm{C} ;{ }^{1} \mathrm{H}$ NMR $(400$ $\left.\mathrm{MHz}, \mathrm{CDCl}_{3}\right) \delta 1.50\left(\mathrm{~s}, 18 \mathrm{H}, \mathrm{CH}_{3}\right), 3.05-3.25(\mathrm{~m}, 4 \mathrm{H}$, piperazine $\left.\mathrm{CH}_{2}\right), 3.70-3.90\left(\mathrm{~m}, 7 \mathrm{H}, \mathrm{CH}_{3}\right.$ and piperazine $\mathrm{CH}_{2}$ ), 6.60-6.75 (m, 2H, pyridine $\mathrm{CH}$ ), 7.05 (s, 1H, H-8), 7.40 (bs, $1 \mathrm{H}, \mathrm{NH}), 7.50(\mathrm{t}, J=6.0 \mathrm{~Hz}, 1 \mathrm{H}$, pyridine $\mathrm{CH}), 8.10(\mathrm{~d}, J=6.0$ $\mathrm{Hz}, 1 \mathrm{H}$, pyridine $\mathrm{CH}$ ), 8.70 (s, $1 \mathrm{H}, \mathrm{H}-5), 9.40$ (s, 1H, H-2), 10.80 (bs, $1 \mathrm{H}, \mathrm{NH}), 12.40$ (s, $1 \mathrm{H}, \mathrm{COOH})$.

\subsubsection{6-Guanidino-1-Methyl-4-Oxo-7-(4-(Pyridin2-yl) Pipe- razin -1-yl])-1,4-Dihydroquinoline-3-Carboxylic Acid (1)}

$\mathrm{HCl}$ was bubbled through a solution of compound $\mathbf{1 3}(0.10$ $\mathrm{g}, 1.74 \mathrm{mmol})$ in a mixture of absolute EtOH $(10 \mathrm{~mL})$ and $\mathrm{CHCl}_{3}(10 \mathrm{~mL})$, at room temperature. After $15 \mathrm{~h}$, the obtained precipitate was collected by filtration, washed with a mixture of $\mathrm{EtOH} / \mathrm{CHCl}_{3}(1: 1)$, and dried, to give $\mathbf{1}(0.018 \mathrm{~g}, 26 \%)$ : $\mathrm{mp}$ $>300{ }^{\circ} \mathrm{C} ;{ }^{1} \mathrm{H}$ NMR (400 MHz, DMSO- $d_{6}$ ) $\delta 3.10-3.25$ and 4.10-4.25 (m, each $4 \mathrm{H}$, piperazine $\left.\mathrm{CH}_{2}\right), 3.90\left(\mathrm{~s}, 3 \mathrm{H}, \mathrm{CH}_{3}\right)$, 7.00 (t, $J=6.4 \mathrm{~Hz}, 1 \mathrm{H}$, pyridine $\mathrm{CH}$ ), $7.30(\mathrm{~s}, 1 \mathrm{H}, \mathrm{H}-8), 7.50$ (d, $J=9.5 \mathrm{~Hz}, 1 \mathrm{H}$, pyridine $\mathrm{CH}), 8.05-8.10(\mathrm{~m}, 2 \mathrm{H}$, pyridine $\mathrm{CH}), 8.25$ (bs, 1H, NH), 8.75 (s, 1H, H-5), 8.90 (s, 1H, H-2), 9.50 (bs, $1 \mathrm{H}, \mathrm{COOH}$ ). Anal. calcd. for $\mathrm{C}_{21} \mathrm{H}_{22} \mathrm{~N}_{6} \mathrm{O}_{3}: \mathrm{C} 59.85, \mathrm{H}$ 5.50, N 23.26, found: C 60.00, H 5.75, N 23.00. 
C $_{6}$ MODIFICATION

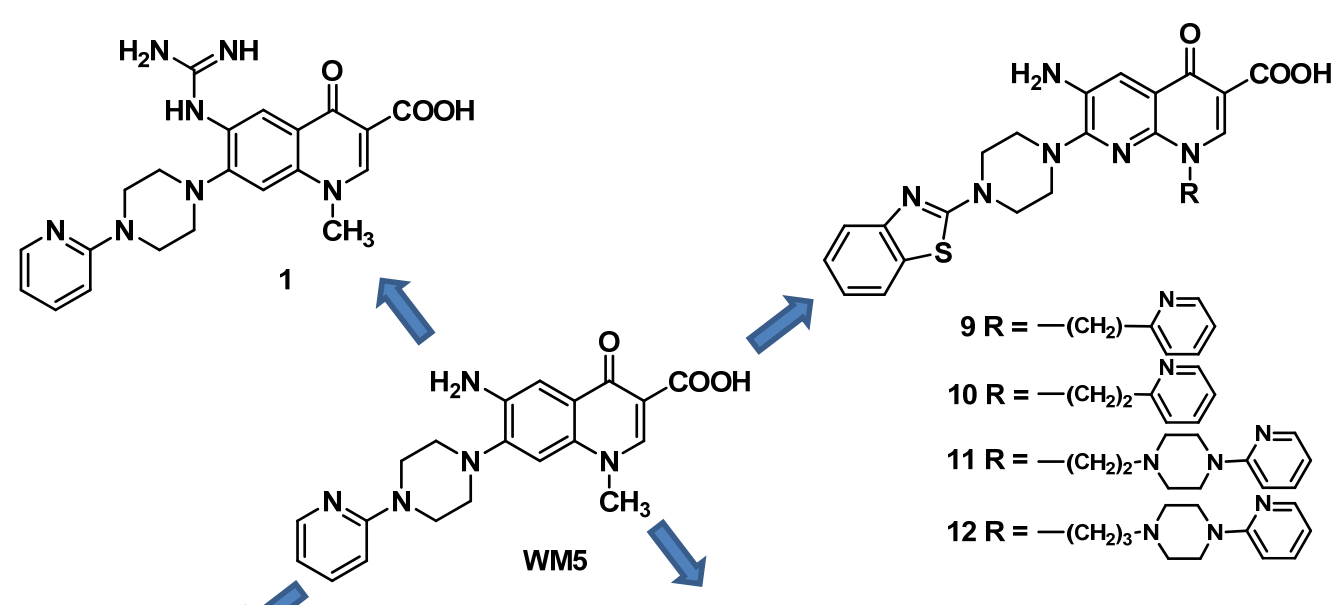

\section{$\mathrm{N}_{1}$ MODIFICATIONS}

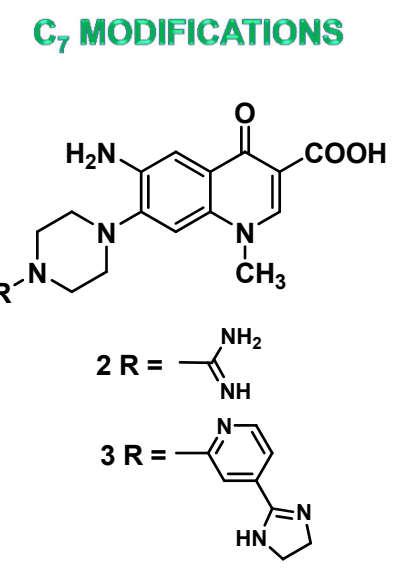

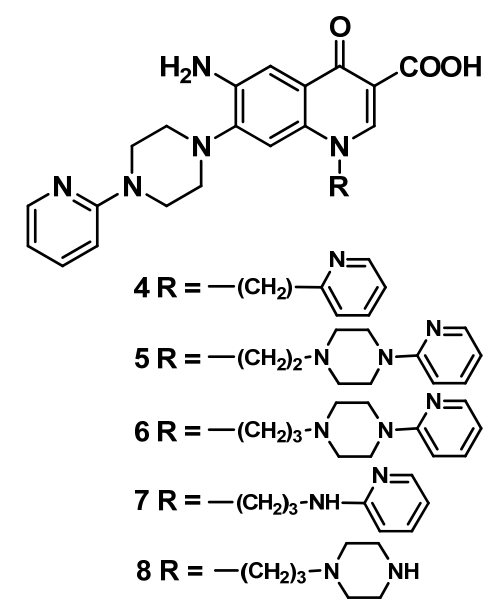

Fig. (1). WM5 analogues characterized by protonable groups.

\subsubsection{Ethyl 7-(4-Carbamidoylpiperazin-1-Yl)-1-Methyl-6- Nitro-4-Oxo-1,4-Dihydroquinoline-3-Carboxylate (15)}

To a solution of synthon 14 [28] (0.70 g, $1.92 \mathrm{mmol})$ in dry DMSO $(50 \mathrm{~mL})$, methyl imidothiocarbamate sulfate $(0.26 \mathrm{~g}$, $0.959 \mathrm{mmol}$ ) was added. The reaction mixture was stirred at $120^{\circ} \mathrm{C}$ for $6 \mathrm{~h}$. After cooling, the precipitate obtained was filtered and dried, to give $\mathbf{1 5}(0.77 \mathrm{~g}, 99 \%)$ : mp $179-181{ }^{\circ} \mathrm{C} ;{ }^{1} \mathrm{H}$ NMR (400 MHz, DMSO- $\left.d_{6}\right) \delta 1.25(\mathrm{t}, J=7.0 \mathrm{~Hz}, 3 \mathrm{H}$, $\mathrm{CH}_{2} \mathrm{CH}_{3}$ ), 3.20-3.30 and 3.60-3.70 (m, each $4 \mathrm{H}$, piperazine $\left.\mathrm{CH}_{2}\right), 3.90\left(\mathrm{~s}, 3 \mathrm{H}, \mathrm{CH}_{3}\right), 4.25$ (q, $J=7.0 \mathrm{~Hz}, 2 \mathrm{H}, \mathrm{CH}_{2} \mathrm{CH}_{3}$ ), 7.15 (s, $1 \mathrm{H}, \mathrm{H}-8), 8.10$ (bs, $3 \mathrm{H}, \mathrm{NH}$ and $\left.\mathrm{NH}_{2}\right), 8.60(\mathrm{~s}, 1 \mathrm{H}$, H-5), 8.70 (s, 1H, H-2).

\subsubsection{6-Amino-7-(4-Carbamidoylpiperazin-1-Yl)-1-Methyl-4- Oxo-1,4-Dihydroquinoline-3-Carboxylic Acid (2)}

To a solution of $15(0.15 \mathrm{~g}, 3.69 \mathrm{mmol})$ in $\mathrm{H}_{2} \mathrm{O}(200 \mathrm{~mL})$ and $\mathrm{NH}_{4} \mathrm{OH}$ conc $(5 \mathrm{~mL})$, a solution of $\mathrm{FeSO}_{4}(0.71 \mathrm{~g}, 2.58$ mmol) in the minimum amount of $\mathrm{H}_{2} \mathrm{O}$ was added and the mixture was stirred at room temperature. After $1 \mathrm{~h}$, the reaction mixture was filtered over Celite $\AA$ and the filtrate was evaporated to dryness to give a residue that was crystallized from $\mathrm{H}_{2} \mathrm{O}$ yielding ethyl 6-amino-7-(4-carbamimidoylpiperazin-1-yl)-1-methyl-4-oxo-1,4-dihydroquinoline-3-carboxylate $(0.08 \mathrm{~g}, 58 \%)$, which was used in the next step without further purification. Thus, ethyl 6-amino-7-(4-carbamimidoylpiperazin-1-yl)-1-methyl-4-oxo-1,4-dihydroquino-line-3carboxylate $(0.08 \mathrm{~g}, 0.21 \mathrm{mmol})$ was dissolved in EtOH $(3 \mathrm{~mL})$ and $6 \mathrm{~N} \mathrm{HCl}(3 \mathrm{~mL})$ was added. The reaction mixture was stirred at reflux for $7 \mathrm{~h}$. After cooling, the precipitate obtained was filtrated, washed with EtOH, and purified by crystallization from $\mathrm{MeOH} / \mathrm{DMF}$, to give $2(0.013 \mathrm{~g}, 17 \%)$ : $\mathrm{mp}$ $>300{ }^{\circ} \mathrm{C} ;{ }^{1} \mathrm{H}$ NMR (400 MHz, DMSO- $d_{6}$ ) $\delta 2.90-3.20$ and 3.60-3.90 (m, each $4 \mathrm{H}$, piperazine $\left.\mathrm{CH}_{2}\right), 3.90\left(\mathrm{~s}, 3 \mathrm{H}, \mathrm{CH}_{3}\right)$, 7.20 (s, 1H, H-8), 7.50 (s, 1H, H-5), 7.90 (bs, 3H, NH e NH$)_{2}$, 8.80 (s, $1 \mathrm{H}, \mathrm{H}-2)$. Anal. calcd. for $\mathrm{C}_{16} \mathrm{H}_{20} \mathrm{~N}_{6} \mathrm{O}_{3}: \mathrm{C} 55.80, \mathrm{H} 5.85$, N 24.40, found: C 55.63, H 5.98, N 24.35.

\subsubsection{1-[4-(4,5-Dihydro-1h-Imidazol-2-Yl)Pyridin-2-Yl]Pipe- razine (18)}

A mixture of 16 [29] (0.50 g, $26.1 \mathrm{mmol})$, ethylenediamine $(0.17 \mathrm{~g}, 2.87 \mathrm{mmol})$, and $p$-toluenesulfonic acid $(0.54 \mathrm{~g}, 2.87$ 
mmol) was reacted under reflux for $3 \mathrm{~h}$. After cooling, the reaction mixture was diluted with $\mathrm{H}_{2} \mathrm{O}$ and then extracted with $\mathrm{CHCl}_{3}$. The organic layers were dried and evaporated to dryness to give $18(0.40 \mathrm{~g}, 66 \%)$ as an oil; ${ }^{1} \mathrm{H}$ NMR $(400 \mathrm{MHz}$, DMSO- $\left.d_{6}\right) \delta 2.70-2.80$ and 3.20-3.30 (m, each $4 \mathrm{H}$, piperazine $\mathrm{CH}_{2}$ ), 3.65 (bs, 4H, imidazoline $\mathrm{CH}_{2}$ ), 3.80 (bs, $1 \mathrm{H}, \mathrm{NH}$ ), 7.00 $(\mathrm{d}, J=5.0 \mathrm{~Hz}, 1 \mathrm{H}$, pyridine $\mathrm{CH}), 7.20(\mathrm{~s}, 1 \mathrm{H}$, pyridine $\mathrm{CH})$, 8.20 (s, $1 \mathrm{H}$, pyridine $\mathrm{CH})$.

\subsubsection{General Procedure for the C-7 Nucleophilic Substitution Reaction (Method A)}

A mixture of the selected synthon (1.0 equiv), the appropriate base (3.0 equiv), and $\mathrm{K}_{2} \mathrm{CO}_{3}$ (3.0 equiv) in dry DMF was stirred at $40-80^{\circ} \mathrm{C}$ until no starting material was detected by TLC (2-72 h). After cooling, the reaction mixture was poured into ice/water yielding a precipitate which was washed with water and then with $\mathrm{Et}_{2} \mathrm{O}$, and further purified as reported in the description of the compounds.

\subsubsection{Ethyl 7-(4-(4-(4,5-Dihydro-1h-Imidazol-2-Yl)Pyridin2- yl)Piperazin-1-yl])-1-Methyl-6-Nitro-4-Oxo-1,4- Dihydroquinoline-3-Carboxylate (19)}

The title compound was obtained starting from 17 [20] and 18 using Method A $\left(80^{\circ} \mathrm{C}, 6 \mathrm{~h}\right)$ after crystallization from DMF in $88 \%$ yield: $\mathrm{mp} 255-256{ }^{\circ} \mathrm{C} ;{ }^{1} \mathrm{H}$ NMR (400 MHz, DMSO- $d_{6}$ ) $\delta 1.25\left(\mathrm{t}, J=7.0 \mathrm{~Hz}, 3 \mathrm{H}, \mathrm{CH}_{2} \mathrm{CH}_{3}\right), 3.30-3.40$ and $3.70-3.75$ (m, each $4 \mathrm{H}$, piperazine $\mathrm{CH}_{2}$ ), $3.80\left(\mathrm{bs}, 4 \mathrm{H}\right.$, imidazoline $\mathrm{CH}_{2}$ ), $3.95\left(\mathrm{~s}, 3 \mathrm{H}, \mathrm{CH}_{3}\right), 4.25$ (q, $\left.J=7.0 \mathrm{~Hz}, 2 \mathrm{H}, \mathrm{CH}_{2} \mathrm{CH}_{3}\right), 7.05$ (d, $J$ $=5.0 \mathrm{~Hz}, 1 \mathrm{H}$, pyridine $\mathrm{CH}), 7.10-7.15(\mathrm{~m}, 1 \mathrm{H}$, pyridine $\mathrm{CH})$, 7.20 (s, $1 \mathrm{H}, \mathrm{H}-8), 8.20$ (d, J = 5.0 Hz, $1 \mathrm{H}$, pyridine $\mathrm{CH}), 8.55$ (s, 1H, H-2), 8.70 (s, 1H, H-5).

\subsubsection{General Procedure for Reduction of C-6 Nitro Group (Method B)}

A stirred solution of the selected 6-nitroderivative in DMF was hydrogenated over a catalytic amount of Raney nickel under atmospheric pressure at room temperature until no starting material was detected by TLC (15 min-3 h). The mixture was then filtered over Celite, and the filtrate was evaporated to dryness to afford a residue that was treated with $\mathrm{EtOH} / \mathrm{Et}_{2} \mathrm{O}$ yielding a solid that was filtered and dried.

\subsubsection{Ethyl 6-Amino-7-(4-(4-(4,5-Dihydro-1h-Imidazol-2- Yl)Pyridin2-yl)Piperazin-1-yl])-1-Methyl-4-Oxo-1,4- Dihydroquinoline-3-Carboxylate (20)}

The title compound was obtained starting from 19 using Method B (3 h) after purification by flash chromatography eluting with $\mathrm{CH}_{2} \mathrm{Cl}_{2} / \mathrm{MeOH}$ (9:1) in $58 \%$ yield: $\mathrm{mp} 300{ }^{\circ} \mathrm{C}$ (dec); ${ }^{1} \mathrm{H}$ NMR (200 MHz, DMSO- $\left.d_{6}\right) \delta 1.25$ (t, $J=7.0 \mathrm{~Hz}$, $\left.3 \mathrm{H}, \mathrm{CH}_{2} \mathrm{CH}_{3}\right), 3.05-3.10$ and 3.50-3.55 (m, each $4 \mathrm{H}$, piperazine $\left.\mathrm{CH}_{2}\right), 3.80$ (bs, $4 \mathrm{H}$, imidazoline $\left.\mathrm{CH}_{2}\right), 3.90\left(\mathrm{~s}, 3 \mathrm{H}, \mathrm{CH}_{3}\right), 4.20$ (q, $\left.J=7.0 \mathrm{~Hz}, 2 \mathrm{H}, \mathrm{CH}_{2} \mathrm{CH}_{3}\right), 5.25$ (bs, $\left.2 \mathrm{H}, \mathrm{NH}_{2}\right), 7.00(\mathrm{~s}, 1 \mathrm{H}$, $\mathrm{H}-8), 7.15$ (d, $J=5.0 \mathrm{~Hz}, 1 \mathrm{H}$, pyridine $\mathrm{CH}), 7.45$ (s, 1H, H-5), 7.60-7.65 (m, $1 \mathrm{H}$, pyridine $\mathrm{CH}), 8.30(\mathrm{~d}, J=5.0 \mathrm{~Hz}, 1 \mathrm{H}$, pyridine $\mathrm{CH}), 8.40$ (s, 1H, H-2).

\subsubsection{General Procedure for Basic Hydrolysis (Method C)}

A suspension of selected ethyl ester ( 0.3 mequiv) in $4 \%$ $\mathrm{NaOH}(5 \mathrm{~mL})$ was refluxed until no starting material could be detected by TLC (4-20 h). After cooling the reaction mixture was acidified to $\mathrm{pH}=4$ with $2 \mathrm{~N} \mathrm{HCl}$, obtaining a precipitate which was filtered, washed with water, and purified as described below.

2.1.11. 6-Amino-7-\{4-[4-(4,5-Dihydro-1h-Imidazol-2-Yl) Pyridin -2-Yl]Piperazin-1-Yl\}-1-Methyl-4-Oxo-1,4-Dihydroquinoline-3-Carboxylic Acid (3)

The title compound was obtained starting from $\mathbf{2 0}$ using Method C (15 h) after crystallization from DMF in 32\% yield: $\mathrm{mp}>300{ }^{\circ} \mathrm{C} ;{ }^{1} \mathrm{H}$ NMR $\left(400 \mathrm{MHz}\right.$, DMSO- $\left.d_{6}\right) \delta 2.80-2.90$ and 3.00-3.25 (m, each $4 \mathrm{H}$, piperazine $\left.\mathrm{CH}_{2}\right), 3.50$ (bs, $4 \mathrm{H}$, imidazoline $\left.\mathrm{CH}_{2}\right), 3.90\left(\mathrm{~s}, 3 \mathrm{H}, \mathrm{CH}_{3}\right), 5.00(\mathrm{bs}, 1 \mathrm{H}, \mathrm{NH}), 5.50$ (bs, $\left.2 \mathrm{H}, \mathrm{NH}_{2}\right), 6.90(\mathrm{~s}, 1 \mathrm{H}, \mathrm{H}-8), 7.10-7.25(\mathrm{~m}, 2 \mathrm{H}$, pyridine $\mathrm{CH}), 7.50(\mathrm{~s}, 1 \mathrm{H}, \mathrm{H}-5), 8.25(\mathrm{~d}, J=5.0 \mathrm{~Hz}, 1 \mathrm{H}$, pyridine $\mathrm{CH})$, $8.75(\mathrm{~s}, 1 \mathrm{H}, \mathrm{H}-2), 11.20(\mathrm{COOH})$. Anal. calcd. for $\mathrm{C}_{23} \mathrm{H}_{25} \mathrm{~N}_{7} \mathrm{O}_{3}$ : C 61.73, H 5.63, N 21.91, found: C 61.98, H 5.82, N 21.73.

\subsubsection{General Procedure for the Cycloaracylation Reaction, Step 1 (Method D)}

A mixture of acrylate (1.0 equiv) and appropriate amine (1.2 equiv) in a mixture of $\mathrm{Et}_{2} \mathrm{O} / \mathrm{EtOH}(3: 1)$, was stirred at room temperature until no starting material was detected by TLC (30 min-2 h). The reaction mixture was then concentrated in vacuo, yielding a residue which was used in the consecutive step without further purification.

\subsubsection{Ethyl 2-(2,4-Dichloro-5-Nitrobenzoyl)-3-(Pyridin-2- Ylmethylamino)Acrylate (22)}

The title compound was obtained starting from 21 [30] and (pyridin-2-ylmethyl)amine using Method D (2 h) in 78\% yield: mp 98-99 ${ }^{\circ} \mathrm{C}$; ${ }^{1} \mathrm{H}-\mathrm{NMR}\left(200 \mathrm{MHz}, \mathrm{CDCl}_{3}\right) \delta 1.00$ (t, $J=7.1$ $\left.\mathrm{Hz}, 3 \mathrm{H}, \mathrm{CH}_{2} \mathrm{CH}_{3}\right), 4.00$ (q, $\left.J=7.1 \mathrm{~Hz}, 2 \mathrm{H}, \mathrm{CH}_{2} \mathrm{CH}_{3}\right), 4.75$ (d, $J$ $\left.=5.9 \mathrm{~Hz}, 2 \mathrm{H}, \mathrm{CH}_{2}\right), 7.15-7.25(\mathrm{~m}, 2 \mathrm{H}$, pyridine $\mathrm{CH}), 7.50(\mathrm{~s}$, 1H, H-3'), 7.70-7.80 (m, 2H, pyridine $\mathrm{CH}$ and H-6'), 8.30 (d, $J$ $=14.0 \mathrm{~Hz}, 1 \mathrm{H}$, vinyl $\mathrm{CH}), 8.65-8.75(\mathrm{~m}, 1 \mathrm{H}$, pyridine $\mathrm{CH})$, $11.40-11.50(\mathrm{~m}, 1 \mathrm{H}, \mathrm{NH})$.

\subsubsection{Ethyl 3-[(3-Bromopropyl)Amino]-2-(2,4-Dichloro-5- Nitrobenzoyl)Acrylate (23)}

The title compound was obtained starting from 21 [30] and (3-bromopropyl)amine using Method D (30 $\mathrm{min}$ ) as keto-enolic mixture in $66 \%$ yield: $\mathrm{mp} 66-67{ }^{\circ} \mathrm{C}$; ${ }^{1} \mathrm{H}-\mathrm{NMR}(200, \mathrm{MHz}$, DMSO- $d_{6}$ ) $\delta 0.75$ and 0.90 (t, $J=7.0 \mathrm{~Hz}, 0.75$ and $2.25 \mathrm{H}$, $\left.\mathrm{CH}_{2} \mathrm{CH}_{3}\right), 2.10-2.25\left(\mathrm{~m}, 2 \mathrm{H}, \mathrm{CH}_{2}\right), 3.50-3.75\left(\mathrm{~m}, 4 \mathrm{H}, \mathrm{CH}_{2}\right)$, 3.90 (q, $\left.J=7.0 \mathrm{~Hz}, 2 \mathrm{H}, \mathrm{CH}_{2} \mathrm{CH}_{3}\right), 4.20(\mathrm{bs}, 1 \mathrm{H}, \mathrm{NH}), 8.10$ (s, 2H, H-3' and H-6'), 8.20-8.25 (m, 1H, vinyl $\mathrm{CH}$ ), 9.75 (bs, $0.75 \mathrm{H}, \mathrm{OH}), 10.90$ (bs, $0.25 \mathrm{H}, \mathrm{NH}$ ).

\subsubsection{Ethyl 2-(2,4-Dichloro-5-Nitrobenzoyl) -3-\{[3-(Pyridin -2 -Ylamino)Propyl]Amino\}Prop-2-Enoate (24)}

The title compound was obtained as an oil, starting from 21 [30] and $N$-(pyridine-2-yl)propane-1,3-diamine [31] using Method D (30 min) in 29\% yield; ${ }^{1} \mathrm{H}-\mathrm{NMR}\left(200 \mathrm{MHz}, \mathrm{CDCl}_{3}\right)$ 
$\delta 1.05\left(\mathrm{t}, J=7.1 \mathrm{~Hz}, 3 \mathrm{H}, \mathrm{CH}_{2} \mathrm{CH}_{3}\right), 1.90-2.00(\mathrm{~m}, 2 \mathrm{H}$, $\mathrm{CH}_{2} \mathrm{CH}_{2} \mathrm{CH}_{2}$ ), 3.50-3.60 (m, 4H, $\mathrm{CH}_{2} \mathrm{CH}_{2} \mathrm{CH}_{2}$ ), 3.95-4.05 (q, $\mathrm{J}$ $\left.=7.1 \mathrm{~Hz}, 2 \mathrm{H}, \mathrm{CH}_{2} \mathrm{CH}_{3}\right), 4.50(\mathrm{bs}, 1 \mathrm{H}, \mathrm{NH}) 6.35-6.45(\mathrm{~m}, 1 \mathrm{H}$, pyridine $\mathrm{CH}), 6.60-6.70(\mathrm{~m}, 1 \mathrm{H}$, pyridine $\mathrm{CH}), 7.30-7.40(\mathrm{~m}$, $1 \mathrm{H}$, pyridine $\mathrm{CH}), 7.55$ (s, 1H, H-3'), 8.75 (s, 1H, H-6'), 8.20-8.30 (m, $2 \mathrm{H}$, vinyl $\mathrm{CH}$ and pyridine $\mathrm{CH}), 11.25$ (bs, $1 \mathrm{H}$, $\mathrm{NH})$.

\subsubsection{General Procedure For The Cycloaracylation Reaction, Step 2 (Method E)}

A mixture of acrylate intermediate (1.0 equiv) and $\mathrm{K}_{2} \mathrm{CO}_{3}$ (3.0 equiv) in dry DMF was heated at $80^{\circ} \mathrm{C}$ for $1 \mathrm{~h}$. After cooling, the reaction mixture was poured into ice/water, giving a precipitate that was filtered, washed with water and then with $\mathrm{Et}_{2} \mathrm{O}$.

\subsubsection{Ethyl 7-Chloro -6-Nitro-4 -Oxo-1- (Pyridin -2- Ylmethyl) -1,4- Dihydroquinoline- 3-Carboxylate (25)}

The title compound was obtained starting from 22 using Method E in $86 \%$ yield: $\mathrm{mp} 228-230{ }^{\circ} \mathrm{C} ;{ }^{1} \mathrm{H}$ NMR $(400 \mathrm{MHz}$, $\left.\mathrm{CDCl}_{3}\right) \delta 1.30\left(\mathrm{t}, J=7.1 \mathrm{~Hz}, 3 \mathrm{H}, \mathrm{CH}_{2} \mathrm{CH}_{3}\right), 4.45(\mathrm{q}, J=7.1 \mathrm{~Hz}$, $\left.2 \mathrm{H}, \mathrm{CH}_{2} \mathrm{CH}_{3}\right), 5.40\left(\mathrm{~s}, 2 \mathrm{H}, \mathrm{CH}_{2}\right), 7.20-7.30(\mathrm{~m}, 2 \mathrm{H}$, pyridine $\mathrm{CH}), 7.55(\mathrm{~s}, 1 \mathrm{H}, \mathrm{H}-8), 7.65-7.75(\mathrm{~m}, 1 \mathrm{H}$, pyridine $\mathrm{CH})$, 8.50-8.60 (m, 2H, pyridine $\mathrm{CH}$ and $\mathrm{H}-2), 8.95$ (s, 1H, H-5).

\subsubsection{Ethyl 1-(3-Bromopropyl)-7-Chloro-6-Nitro-4-Oxo-1,4- Dihydroquinoline-3-Carboxylate (26)}

The title compound was obtained starting from 23 using Method E in $88 \%$ yield: $m p 180-181{ }^{\circ} \mathrm{C} ;{ }^{1} \mathrm{H}$ NMR $(400 \mathrm{MHz}$, DMSO- $\left.d_{6}\right) \delta 1.30\left(\mathrm{t}, J=7.0 \mathrm{~Hz}, 3 \mathrm{H}, \mathrm{CH}_{2} \mathrm{CH}_{3}\right), 2.15-2.30(\mathrm{~m}$, $2 \mathrm{H}, \mathrm{CH}_{2} \mathrm{CH}_{2} \mathrm{CH}_{2}$ ), 3.70 (t, $\left.J=7,5 \mathrm{~Hz}, 2 \mathrm{H}, \mathrm{NCH}_{2}\right) 4.25$ (q, $J=$ $\left.7.0 \mathrm{~Hz}, 2 \mathrm{H}, \mathrm{CH}_{2} \mathrm{CH}_{3}\right), 4.50-4.60\left(\mathrm{~m}, 2 \mathrm{H}, \mathrm{CH}_{2} \mathrm{Br}\right), 8.25$ (s, $1 \mathrm{H}$, H-8), 8.75 (s, 1H, H-5), 8.80 (s, 1H, H-2).

\subsubsection{Ethyl 7- Chloro- 6-Nitro-4-Oxo-1- [3-(Pyridin-2- Ylamino) Propyl]-1,4- Dihydroquinoline-3-Carboxylate (27)}

The title compound was obtained starting from 24 using Method E in $77 \%$ yield: mp $148-149{ }^{\circ} \mathrm{C} ;{ }^{1} \mathrm{H}$ NMR $(400 \mathrm{MHz}$, $\left.\mathrm{CDCl}_{3}\right) \delta 1.40\left(\mathrm{t}, J=7.1 \mathrm{~Hz}, 3 \mathrm{H}, \mathrm{CH}_{2} \mathrm{CH}_{3}\right), 2.20-2.30(\mathrm{~m}, 2 \mathrm{H}$, $\mathrm{CH}_{2} \mathrm{CH}_{2} \mathrm{CH}_{2}$ ) 3.50-3.60 (m, 2H, $\left.\mathrm{NCH}_{2}\right), 4.30-4.45$ (m, 4H, $\mathrm{CH}_{2} \mathrm{NH}$ and $\left.\mathrm{CH}_{2} \mathrm{CH}_{3}\right), 4.60-4.70(\mathrm{~m}, 1 \mathrm{H}, \mathrm{NH}), 6.40-6.50$ and 6.55-6.65 and 7.40-7.50 (m, each $1 \mathrm{H}$, pyridine $\mathrm{CH}), 7.75(\mathrm{~s}$, $1 \mathrm{H}, \mathrm{H}-8), 8.00-8.10(\mathrm{~m}, 1 \mathrm{H}$, pyridine $\mathrm{CH}), 8.60(\mathrm{~s}, 1 \mathrm{H}, \mathrm{H}-2)$, $9.00(\mathrm{~s}, 1 \mathrm{H}, \mathrm{H}-5)$.

2.1.20. Ethyl 6- Nitro -4-Oxo-1- (Pyridin-2-Ylmethyl) -7-(4(Pyridin2-yl) Piperazin-1-yl]) -1,4- Dihydroquinoline -3Carboxylate (28)

The title compound was obtained starting from $\mathbf{2 5}$ and 1(2-pyridinyl)piperazine using Method A $\left(80^{\circ} \mathrm{C}, 2 \mathrm{~h}\right)$ in $88 \%$ yield: $\mathrm{mp} 181-183{ }^{\circ} \mathrm{C} ;{ }^{1} \mathrm{H}$ NMR $\left(400 \mathrm{MHz}, \mathrm{CDCl}_{3}\right) \delta 1.35$ (t, $J$ $\left.=7.0 \mathrm{~Hz}, 3 \mathrm{H}, \mathrm{CH}_{2} \mathrm{CH}_{3}\right), 3.05-3.15$ and 3.55-3.65 (m, each $4 \mathrm{H}$, piperazine $\left.\mathrm{CH}_{2}\right), 4.45\left(\mathrm{q}, \mathrm{J}=7.0 \mathrm{~Hz}, 2 \mathrm{H}, \mathrm{CH}_{2} \mathrm{CH}_{3}\right), 5.35(\mathrm{~s}, 2 \mathrm{H}$, $\left.\mathrm{CH}_{2}\right)$, 6.60-6.70 (m, 2H, pyridine $\left.\mathrm{CH}\right), 6.90(\mathrm{~s}, 1 \mathrm{H}, \mathrm{H}-8)$, 7.15-7.30 (m, 2H, pyridine $\mathrm{CH}), 7.40-7.50,7.60-7.70$, and 8.15-8.25 (m, each $1 \mathrm{H}$, pyridine $\mathrm{CH}), 8.60-8.65(\mathrm{~m}, 2 \mathrm{H}, \mathrm{H}-2$ and pyridine $\mathrm{CH}), 8.80$ (s, 1H, H-5).
2.1.21. Ethyl 6-Nitro-4-Oxo-7-(4-(Pyridin2-yl)Piperazin-1yl])-1-[3-(4-(Pyridin2-yl)Piperazin-1-yl])Propyl]-1,4Dihydroquinoline-3-Carboxylate (29) And Ethyl 1-(3Bromopropyl)-6-Nitro-4-Oxo-7-(4-(Pyridin2-yl)Piperazin-1yl])-1,4-Dihydroquinoline-3-Carboxylate (30)

The title compounds were obtained starting from $\mathbf{2 6}$ and 1(2-pyridinyl)piperazine using Method $\mathrm{A}\left(40^{\circ} \mathrm{C}, 72 \mathrm{~h}\right)$ after purification by flash chromatography eluting with $\mathrm{CHCl}_{3} /$ $\mathrm{MeOH}$ (from 100:0 to 80:20) in 53\% yield (compound 29) and $23 \%$ yield (compound 30); compound 29: $\mathrm{mp} 89-91{ }^{\circ} \mathrm{C}$; ${ }^{1} \mathrm{H}$ NMR (400 MHz, $\left.\mathrm{CDCl}_{3}\right) \delta 1.40\left(\mathrm{t}, J=7.0 \mathrm{~Hz}, 3 \mathrm{H}, \mathrm{CH}_{2} \mathrm{CH}_{3}\right)$, 2.05-2.10 and 2.40-2.45 (m, each $\left.2 \mathrm{H}, \mathrm{CH}_{2}\right), 2.50-2.60$, $3.25-3.35,3.50-3.60$ and $3.75-3.85(\mathrm{~m}$, each $4 \mathrm{H}$, piperazine $\left.\mathrm{CH}_{2}\right), 4.25-4.45\left(\mathrm{~m}, 4 \mathrm{H}, \mathrm{CH}_{2} \mathrm{CH}_{3}\right.$ and $\left.\mathrm{CH}_{2}\right), 6.60-6.75(\mathrm{~m}, 4 \mathrm{H}$, pyridine $\mathrm{CH}), 6.90(\mathrm{~s}, 1 \mathrm{H}, \mathrm{H}-8), 7.45-7.55$ and 8.15-8.25 (m, each $2 \mathrm{H}$, pyridine $\mathrm{CH}), 8.60$ (s, $1 \mathrm{H}, \mathrm{H}-5), 8.80(\mathrm{~s}, 1 \mathrm{H}, \mathrm{H}-2)$; compound 30: $\mathrm{mp} 209-210{ }^{\circ} \mathrm{C} ;{ }^{1} \mathrm{H}$ NMR $\left(400 \mathrm{MHz}, \mathrm{CDCl}_{3}\right) \delta$ 1.40 (t, $\left.J=7.0 \mathrm{~Hz}, 3 \mathrm{H}, \mathrm{CH}_{2} \mathrm{CH}_{3}\right), 2.30-2.50\left(\mathrm{~m}, 2 \mathrm{H}, \mathrm{CH}_{2}\right)$, 3.25-3.40 (m, 4H, piperazine $\left.\mathrm{CH}_{2}\right), 3.60-3.80(\mathrm{~m}, 6 \mathrm{H}$, piperazine $\mathrm{CH}_{2}$ and $\left.\mathrm{CH}_{2}\right), 4.30-4.50\left(\mathrm{~m}, 4 \mathrm{H}, \mathrm{CH}_{2} \mathrm{CH}_{3}\right.$ and $\left.\mathrm{CH}_{2}\right)$, 6.60-6.75 (m, 2H, pyridine $\mathrm{CH}), 7.00(\mathrm{~s}, 1 \mathrm{H}, \mathrm{H}-8), 7.50(\mathrm{t}, J=$ $6.4 \mathrm{~Hz}, 1 \mathrm{H}$, pyridine $\mathrm{CH}), 8.15-8.25(\mathrm{~m}, 1 \mathrm{H}$, pyridine $\mathrm{CH})$, 8.40 (s, 1H, H-5), 8.80 (s, 1H, H-2).

2.1.22. Ethyl 6- Nitro -4-Oxo-1- [3-(Pyridin-2-Ylamino) Propyl]-7- (4-(Pyridin2-yl) Piperazin-1-yl]) -1,4- Dihydroquinoline -3- Carboxylate (31)

The title compound was obtained starting from 27 and 1(2-pyridinyl)piperazine using Method $\mathrm{A}\left(80^{\circ} \mathrm{C}, 3 \mathrm{~h}\right)$, in $100 \%$ yield: mp 124-125 ${ }^{\circ} \mathrm{C} ;{ }^{1} \mathrm{H}$ NMR (400 MHz, $\left.\mathrm{CDCl}_{3}\right) \delta 1.40(\mathrm{t}, J$ $\left.=7.1 \mathrm{~Hz}, 3 \mathrm{H}, \mathrm{CH}_{2} \mathrm{CH}_{3}\right), 2.20-2.30\left(\mathrm{~m}, 2 \mathrm{H}, \mathrm{NCH}_{2} \mathrm{CH}_{2} \mathrm{CH}_{2} \mathrm{NH}\right)$, 3.10-3.20 (m, 4H, piperazine $\left.\mathrm{CH}_{2}\right), 3.50-3.60(\mathrm{~m}, 2 \mathrm{H}$, $\left.\mathrm{NCH}_{2} \mathrm{CH}_{2} \mathrm{CH}_{2} \mathrm{NH}\right), 3.65-3.75\left(\mathrm{~m}, 4 \mathrm{H}\right.$, piperazine $\left.\mathrm{CH}_{2}\right)$, 4.25-4.40 (m, $4 \mathrm{H}, \mathrm{NCH}_{2} \mathrm{CH}_{2} \mathrm{CH}_{2} \mathrm{NH}$ and $\left.\mathrm{CH}_{2} \mathrm{CH}_{3}\right), 4.75-4.85$ $(\mathrm{m}, 1 \mathrm{H}, \mathrm{NH}), 6.35-6.45(\mathrm{~m}, 1 \mathrm{H}$, pyridine $\mathrm{CH}), 6.55-6.70(\mathrm{~m}$, $3 \mathrm{H}$, pyridine $\mathrm{CH}$ ), $6.80(\mathrm{~s}, 1 \mathrm{H}, \mathrm{H}-8), 7.30-7.40,7.45-7.55$, 8.05-8.15, and 8.15-8.25 (m, each $1 \mathrm{H}$, pyridine $\mathrm{CH}), 8.45$ (s, $1 \mathrm{H}, \mathrm{H}-5), 8.85$ (s, 1H, H-2).

\subsubsection{Ethyl 6-Nitro-4-Oxo-1-(3-(Piperazin-1-Yl)Propyl)-7- (4-(Pyridin2-yl)Piperazin-1-yl])-1,4-Dihydroquinoline-3- Carboxylate (32)}

Piperazine (0.08 g, $9.39 \mathrm{mmol})$ and DIPEA (0.12 g, 9.38 $\mathrm{mmol})$ were added to a solution of $\mathbf{3 0}(0.13 \mathrm{~g}, 2.34 \mathrm{mmol})$ in dry DMF $(5 \mathrm{~mL})$, and the mixture was stirred at $80^{\circ} \mathrm{C}$ for $48 \mathrm{~h}$. After cooling, the reaction mixture was evaporated to dryness and the residue was purified by flash chromatography eluting with $\mathrm{CHCl}_{3} / \mathrm{MeOH} / \mathrm{NH}_{4} \mathrm{OH}$ (from 90:10:0 to 79:20:1), to give 32 (0.08 g, 63\%): mp 186-189 ${ }^{\circ} \mathrm{C} ;{ }^{1} \mathrm{H}$ NMR (400 MHz, DMSO- $\left.d_{6}\right) \delta 1.15\left(\mathrm{t}, J=7.0 \mathrm{~Hz}, 3 \mathrm{H}, \mathrm{CH}_{2} \mathrm{CH}_{3}\right), 1.90-2.00$ and 2.10-2.15 (m, each $2 \mathrm{H}, \mathrm{CH}_{2}$ ), 2.20-2.30, 2.90-3.0, 3.10-3.20 and 3.70-3.80 (m, each $4 \mathrm{H}$, piperazine $\left.\mathrm{CH}_{2}\right), 4.10(\mathrm{q}, J=7.0$ $\left.\mathrm{Hz}, 2 \mathrm{H}, \mathrm{CH}_{2} \mathrm{CH}_{3}\right), 4.20-4.30\left(\mathrm{~m}, 2 \mathrm{H}, \mathrm{CH}_{2}\right), 6.70$ (t, $J=6.5 \mathrm{~Hz}$, $1 \mathrm{H}$, pyridine $\mathrm{CH}), 6.90(\mathrm{~d}, J=9.3 \mathrm{~Hz}, 1 \mathrm{H}$, pyridine $\mathrm{CH}), 7.10$ (s, $1 \mathrm{H}, \mathrm{H}-8), 7.60(\mathrm{t}, J=6.5 \mathrm{~Hz}, 1 \mathrm{H}$, pyridine $\mathrm{CH}), 8.10-8.20$ (m, 1H, pyridine $\mathrm{CH}), 8.60$ (s, 1H, H-5), 8.70 (s, 1H, H-2). 
2.1.24. Ethyl 6-Amino-4-Oxo-1-(Pyridin-2-Ylmethyl)-7-(4(Pyridin2-yl)Piperazin-1-yl])-1,4-Dihydroquinoline-3Carboxylate (33)

The title compound was obtained starting from 28 using Method B (45 min) in $34 \%$ yield: $\mathrm{mp} 268-270{ }^{\circ} \mathrm{C}$; ${ }^{1} \mathrm{H}$ NMR $\left(400 \mathrm{MHz}, \mathrm{DMSO}-d_{6}\right) \delta 1.30\left(\mathrm{t}, J=7.0 \mathrm{~Hz}, 3 \mathrm{H}, \mathrm{CH}_{2} \mathrm{CH}_{3}\right.$ ), 2.75-2.85 and 3.60-3.70 (m, each $4 \mathrm{H}$, piperazine $\left.\mathrm{CH}_{2}\right), 4.25(\mathrm{q}$, $\left.J=7.0 \mathrm{~Hz}, 2 \mathrm{H}, \mathrm{CH}_{2} \mathrm{CH}_{3}\right), 5.20$ (bs, $\left.2 \mathrm{H}, \mathrm{NH}_{2}\right), 5.70$ (s, $2 \mathrm{H}$, $\left.\mathrm{CH}_{2}\right), 6.70(\mathrm{t}, J=5.0 \mathrm{~Hz}, 1 \mathrm{H}$, pyridine $\mathrm{CH}), 6.85(\mathrm{~d}, J=8.5$ $\mathrm{Hz}, 1 \mathrm{H}$, pyridine $\mathrm{CH}), 7.00(\mathrm{~s}, 1 \mathrm{H}, \mathrm{H}-8), 7.30(\mathrm{t}, J=5.2 \mathrm{~Hz}$, $1 \mathrm{H}$, pyridine $\mathrm{CH}), 7.35-7.45(\mathrm{~m}, 2 \mathrm{H}, \mathrm{H}-5$ and pyridine $\mathrm{CH}$ ), 7.60 and $7.80(\mathrm{t}, J=7.0 \mathrm{~Hz}$, each $1 \mathrm{H}$, pyridine $\mathrm{CH}), 8.20$ and $8.45(\mathrm{~d}, J=3.7 \mathrm{~Hz}$, each $1 \mathrm{H}$, pyridine $\mathrm{CH}), 8.75$ (s, $1 \mathrm{H}, \mathrm{H}-2)$.

2.1.25. Ethyl 6-Amino-4-Oxo-7-(4-(Pyridin2-yl)Piperazin-1yl])-1-[3-(4-(Pyridin2-yl)Piperazin-1-yl])Propyl]-1,4-

Dihydroquinoline-3-Carboxylate (34)

The title compound was obtained starting from 29 using Method B (1 h) in 88\% yield: mp 233-234 ${ }^{\circ} \mathrm{C}$; ${ }^{1} \mathrm{H}$ NMR (400 MHz, DMSO- $\left.d_{6}\right) \delta 1.25\left(\mathrm{t}, J=7.1 \mathrm{~Hz}, 3 \mathrm{H}, \mathrm{CH}_{2} \mathrm{CH}_{3}\right), 1.90-2.00$ (m, $\left.2 \mathrm{H}, \mathrm{CH}_{2}\right), 2.20-2.40\left(\mathrm{~m}, 6 \mathrm{H}, \mathrm{CH}_{2}\right.$ and piperazine $\mathrm{CH}_{2}$ ), $3.10-3.20$ and $3.40-3.50\left(\mathrm{~m}\right.$, each $4 \mathrm{H}$, piperazine $\mathrm{CH}_{2}$ ), 3.70-3.75 (m, $4 \mathrm{H}$, piperazine $\left.\mathrm{CH}_{2}\right), 4.20(\mathrm{q}, J=7.1 \mathrm{~Hz}, 2 \mathrm{H}$, $\left.\mathrm{CH}_{2} \mathrm{CH}_{3}\right), 4.45-4.50\left(\mathrm{~m}, 2 \mathrm{H}, \mathrm{CH}_{2}\right), 5.25\left(\mathrm{bs}, 2 \mathrm{H}, \mathrm{NH}_{2}\right)$, 6.65-6.70 (m, 2H, pyridine $\mathrm{CH}), 6.80$ and $6.90(\mathrm{~d}, J=5.0 \mathrm{~Hz}$, each $1 \mathrm{H}$, pyridine $\mathrm{CH}), 7.15(\mathrm{~s}, 1 \mathrm{H}, \mathrm{H}-8), 7.45-7.55(\mathrm{~m}, 3 \mathrm{H}$, $\mathrm{H}-5$ and pyridine $\mathrm{CH}), 8.10-8.20(\mathrm{~m}, 2 \mathrm{H}$, pyridine $\mathrm{CH}), 8.50$ (s, $1 \mathrm{H}, \mathrm{H}-2)$.

2.1.26. Ethyl 6 -Amino -4- Oxo-1- [3-(Pyridin-2-Ylamino) Propyl] -7- (4-(Pyridin2-yl) Piperazin-1-yl]) -1,4- Dihydroquinoline-3-Carboxylate (35)

The title compound was obtained starting from 31 using Method B (15 min) in $46 \%$ yield: $\mathrm{mp} 244-245{ }^{\circ} \mathrm{C}$; ${ }^{1} \mathrm{H}$ NMR $\left(400 \mathrm{MHz}, \mathrm{DMSO}-d_{6}\right) \delta 1.25\left(\mathrm{t}, J=7.1 \mathrm{~Hz}, 3 \mathrm{H}, \mathrm{CH}_{2} \mathrm{CH}_{3}\right)$, 1.95-2.05 (m, 2H, $\left.\mathrm{NCH}_{2} \mathrm{CH}_{2} \mathrm{CH}_{2} \mathrm{NH}\right), 2.80-2.95(\mathrm{~m}, 4 \mathrm{H}$, piperazine $\left.\mathrm{CH}_{2}\right), \quad 3.20-3.30\left(\mathrm{~m}, 2 \mathrm{H}, \quad \mathrm{NCH}_{2} \mathrm{CH}_{2} \mathrm{CH}_{2} \mathrm{NH}\right)$, 4.60-4.75 (m, 4H, piperazine $\left.\mathrm{CH}_{2}\right), 4.20(\mathrm{q}, J=7.1 \mathrm{~Hz}, 2 \mathrm{H}$, $\left.\mathrm{CH}_{2} \mathrm{CH}_{3}\right), 4.25-4.35\left(\mathrm{~m}, 2 \mathrm{H}, \mathrm{NCH}_{2} \mathrm{CH}_{2} \mathrm{CH}_{2} \mathrm{NH}\right), 5.25(\mathrm{~s}, 2 \mathrm{H}$, $\left.\mathrm{NH}_{2}\right), 6.40-6.50$ and 6.65-6.75 (m, each $2 \mathrm{H}$, pyridine $\left.\mathrm{CH}\right), 7.00$ (s, 1H, H-8), 7.25-7.35 (m, 1H, pyridine $\mathrm{CH}), 7.50-7.60(\mathrm{~m}$, $2 \mathrm{H}$, pyridine $\mathrm{CH}$ and $\mathrm{H}-5), 7.85-7.95$ and 8.10-8.20 (m, each $1 \mathrm{H}$, pyridine $\mathrm{CH}), 8.50$ (s, $1 \mathrm{H}, \mathrm{H}-2)$.

\subsubsection{Ethyl 6-Amino-4-Oxo-1-(3-(Piperazin-1-Yl)Propyl)-7- (4-(Pyridin2-yl)Piperazin-1-yl])-1,4-Dihydroquinoline-3- Carboxylate (36)}

The title compound was obtained starting from 32 using Method B (40 min) in $88 \%$ yield: $\mathrm{mp} 256-257{ }^{\circ} \mathrm{C}$; ${ }^{1} \mathrm{H}$ NMR $\left(200 \mathrm{MHz}\right.$, methanol- $\left.d_{4}\right) \delta 1.35\left(\mathrm{t}, J=7.0 \mathrm{~Hz}, 3 \mathrm{H}, \mathrm{CH}_{2} \mathrm{CH}_{3}\right)$, 2.05-2.10 (m, $\left.2 \mathrm{H}, \mathrm{CH}_{2}\right), 2.40-2.50\left(\mathrm{~m}, 6 \mathrm{H}, \mathrm{CH}_{2}\right.$ and piperazine $\left.\mathrm{CH}_{2}\right), 2.90-3.00,3.20-3.30$, and $3.70-3.80(\mathrm{~m}$, each $4 \mathrm{H}$, piperazine $\mathrm{CH}_{2}$ ), 4.35 (q, $J=7.0 \mathrm{~Hz}, 2 \mathrm{H}, \mathrm{CH}_{2} \mathrm{CH}_{3}$ ), 4.60-4.65 $\left(\mathrm{m}, 2 \mathrm{H}, \mathrm{CH}_{2}\right), 6.70(\mathrm{t}, J=6.5 \mathrm{~Hz}, 1 \mathrm{H}$, pyridine $\mathrm{CH}), 6.90(\mathrm{~d}, J$ $=9.3 \mathrm{~Hz}, 1 \mathrm{H}$, pyridine $\mathrm{CH}), 7.20(\mathrm{~s}, 1 \mathrm{H}, \mathrm{H}-8), 7.60(\mathrm{t}, J=6.5$ $\mathrm{Hz}, 1 \mathrm{H}$, pyridine $\mathrm{CH}), 7.65$ (s, $1 \mathrm{H}, \mathrm{H}-5), 8.10-8.20(\mathrm{~m}, 1 \mathrm{H}$, pyridine $\mathrm{CH}), 8.70$ (s, $1 \mathrm{H}, \mathrm{H}-2)$.
2.1.28. 6- Amino-4-Oxo-1- (Pyridin-2-Ylmethyl) -7-(4(Pyridin2-yl) Piperazin-1-yl]) -1,4- Dihydroquinoline-3Carboxylic Acid (4)

The title compound was obtained starting from $\mathbf{3 3}$ using Method C $(20 \mathrm{~h})$ after purification by treatment with $\mathrm{Et}_{2} \mathrm{O}$ in $64 \%$ yield: $\mathrm{mp} 287-288{ }^{\circ} \mathrm{C} ;{ }^{1} \mathrm{H}$ NMR (400 MHz, DMSO- $d_{6}$ ) $\delta$ 2.85-2.95 and 3.65-3.75 (m, each $4 \mathrm{H}$, piperazine $\left.\mathrm{CH}_{2}\right), 5.45$ (bs, 2H, $\left.\mathrm{NH}_{2}\right), 5.90\left(\mathrm{~s}, 2 \mathrm{H}, \mathrm{CH}_{2}\right), 6.65(\mathrm{t}, J=5.7 \mathrm{~Hz}, 1 \mathrm{H}$, pyridine $\mathrm{CH}), 6.95(\mathrm{~d}, J=8.6 \mathrm{~Hz}, 1 \mathrm{H}$, pyridine $\mathrm{CH}), 7.20$ (s, $1 \mathrm{H}, \mathrm{H}-8), 7.25-7.35(\mathrm{~m}, 1 \mathrm{H}$, pyridine $\mathrm{CH}), 7.50-7.60(\mathrm{~m}, 3 \mathrm{H}$, $\mathrm{H}-5$ and pyridine $\mathrm{CH}), 7.80(\mathrm{t}, J=7.1 \mathrm{~Hz}, 1 \mathrm{H}$, pyridine $\mathrm{CH}$ ), 8.20 and $8.50(\mathrm{~d}, J=3.3 \mathrm{~Hz}$, each $1 \mathrm{H}$, pyridine $\mathrm{CH}), 9.00$ (s, $1 \mathrm{H}, \mathrm{H}-2), 15.90$ (s, 1H, COOH); ${ }^{13} \mathrm{C}$ NMR (101 MHz, DMSO$\left.d_{6}\right) \delta 45.08(2 \mathrm{C}), 49.90(2 \mathrm{C}), 58.54,106.46,106.88,107.66$, $108.38,113.67,122.78,122.85,123.78,132.67,137.85$, $138.10,142.33,145.67,147.55,148.08,150.01,155.17$, 159.43, 167.47, 176.88. Anal. calcd. for $\mathrm{C}_{25} \mathrm{H}_{24} \mathrm{~N}_{6} \mathrm{O}_{3}: \mathrm{C} 65.78$, H 5.30, N 18.41, found: C 70.03, H 5.32, N 18.48.

\subsubsection{6-Amino-4-Oxo-7-(4-(Pyridin2-yl)Piperazin-1-yl])-1- [3-(4-(Pyridin2-yl)Piperazin-1-yl])Propyl]-1,4- Dihydroquinoline-3-Carboxylic Acid (6)}

The title compound was obtained starting from $\mathbf{3 4}$ using Method C (6 h) after purification by crystallization from DMF in $20 \%$ yield: $\mathrm{mp}>300{ }^{\circ} \mathrm{C} ;{ }^{1} \mathrm{H}$ NMR $\left(400 \mathrm{MHz}, \mathrm{DMSO}-d_{6}\right) \delta$ 2.15-2.25 and 3.0-3.15 (m, each $\left.2 \mathrm{H}, \mathrm{CH}_{2}\right), 3.25-3.70(\mathrm{~m}, 10 \mathrm{H}$, piperazine $\mathrm{CH}_{2}$ ), 3.75-4.00 (m, $4 \mathrm{H}$, piperazine $\left.\mathrm{CH}_{2}\right), 4.25-4.45$ and 4.65-4.80 (m, each $2 \mathrm{H}$, piperazine $\mathrm{CH}_{2}$ and $\left.\mathrm{CH}_{2}\right), 5.50(\mathrm{bs}$, $\left.2 \mathrm{H}, \mathrm{NH}_{2}\right), 6.75$ and $6.95(\mathrm{t}, J=6.4 \mathrm{~Hz}$, each $1 \mathrm{H}$, pyridine $\mathrm{CH}$ ), $7.10(\mathrm{~d}, J=9.0 \mathrm{~Hz}, 1 \mathrm{H}$, pyridine $\mathrm{CH}), 7.30(\mathrm{~s}, 1 \mathrm{H}, \mathrm{H}-8), 7.40$ $(\mathrm{d}, J=9.0 \mathrm{~Hz}, 1 \mathrm{H}$, pyridine $\mathrm{CH}), 7.60(\mathrm{~s}, 1 \mathrm{H}, \mathrm{H}-5), 7.75$ and $7.95(\mathrm{t}, J=6.4 \mathrm{~Hz}$, each $1 \mathrm{H}$, pyridine $\mathrm{CH}), 8.05-8.15(\mathrm{~m}, 2 \mathrm{H}$, pyridine $\mathrm{CH}), 8.80(\mathrm{~s}, 1 \mathrm{H}, \mathrm{H}-2), 11.60(\mathrm{bs}, 1 \mathrm{H}, \mathrm{COOH}) ;{ }^{13} \mathrm{C}$ NMR (101 MHz, DMSO- $d_{6}$ ) $\delta 23.52,42.75,46.51$ (2C), 49.42 (2C), $50.68(2 \mathrm{C}), 51.34,53.00(2 \mathrm{C}), 106.67,107.44(2 \mathrm{C})$, $108.13,113.39,114.49$ (2C), 123.15, 132.23, 135.9, 137.9, 142.31, 145.50, 146.31 (2C), 151.06, 152.93, 153.60, 167.33, 176.74. Anal. calcd. for $\mathrm{C}_{31} \mathrm{H}_{36} \mathrm{~N}_{8} \mathrm{O}_{3}$ : C 65.47, H 6.38, N 19.70, found: C 65.40, H 6.70, N 19.55.

\subsubsection{6-Amino-4-Oxo-1-[3-(Pyridin-2-Ylamino)Propyl]-7- (4-(Pyridin2-yl)Piperazin-1-yl])-1,4-Dihydroquinoline-3- Carboxylic Acid Hydrochloride (7)}

The title compound was obtained starting from $\mathbf{3 5}$ using Method C $(6 \mathrm{~h})$ after purification by treatment with $\mathrm{Et}_{2} \mathrm{O}$ in 91\% yield: $\mathrm{mp} 290{ }^{\circ} \mathrm{C}(\mathrm{c}) ;{ }^{1} \mathrm{H}$ NMR (400 MHz, DMSO- $\left.d_{6}\right) \delta$ 2.00-2.10 (m, $2 \mathrm{H}, \mathrm{CH}_{2} \mathrm{CH}_{2} \mathrm{CH}_{2}$ ), 3.10-3.20 (m, $4 \mathrm{H}$, piperazine $\left.\mathrm{CH}_{2}\right), 3.40-3.50\left(\mathrm{~m}, 2 \mathrm{H}, \mathrm{NCH}_{2}\right), 3.90-4.00(\mathrm{~m}, 4 \mathrm{H}$, piperazine $\mathrm{CH}_{2}$ ), 4.65-4.75 (m, 2H, $\left.\mathrm{CH}_{2} \mathrm{NH}\right), 6.75-6.85$ and 6.90-7.00 (m, each $1 \mathrm{H}$, pyridine $\mathrm{CH}), 7.10-7.20(\mathrm{~m}, 1 \mathrm{H}$, pyridine $\mathrm{CH})$, 7.35-7.45 (m, 2H, H-8 and pyridine $\mathrm{CH}), 7.60$ (s, 1H, H-5), 7.80-8.00 (m, $3 \mathrm{H}$, pyridine $\mathrm{CH}), 8.10-8.20(\mathrm{~m}, 1 \mathrm{H}$, pyridine $\mathrm{CH}), 8.75$ (s, 1H, H-2), 9.35 (s, 1H, NH); ${ }^{13} \mathrm{C}$ NMR (101 MHz, DMSO- $\left.d_{6}\right) \delta 28.42,39.45,46.81$ (2C), 49.62 (2C), 51.63, $106.79,108.62,112.39$ (2C), 112.98, 113.36 (2C), 123.10, 133.11, 135.91, 137.90, 140.91, 144.44 (2C), 146.00, 146.55, $152.45,152.96,167.20,176.64$. Anal. calcd. for $\mathrm{C}_{27} \mathrm{H}_{30} \mathrm{ClN}_{7} \mathrm{O}_{3}$ : 
C 60.50, H 5.64, N 18.29, found: C 60.62, H 5.77, N 18.33 .

\subsubsection{6-Amino-4-Oxo-1-(3-(Piperazin-1-Yl)Propyl)-7-(4- (Pyridin2-yl)Piperazin-1-yl])-1,4-Dihydroquinoline-3- Carboxylic Acid (8)}

The title compound was obtained starting from $\mathbf{3 6}$ using Method C (4 h) after purification by crystallization from DMF in $60 \%$ yield: $\mathrm{mp}>300{ }^{\circ} \mathrm{C} ;{ }^{1} \mathrm{H}$ NMR $\left(400 \mathrm{MHz}, \mathrm{DMSO}-d_{6}\right) \delta$ 2.00-2.20 (m, 2H, $\left.\mathrm{CH}_{2}\right), 3.00-3.25$ and 3.30-3.55 (m, each $8 \mathrm{H}$, piperazine $\left.\mathrm{CH}_{2}\right), 3.90-4.00$ and $4.50-4.60\left(\mathrm{~m}\right.$, each $\left.2 \mathrm{H}, \mathrm{CH}_{2}\right)$, $6.90(\mathrm{t}, J=6.5 \mathrm{~Hz}, 1 \mathrm{H}$, pyridine $\mathrm{CH}), 7.20(\mathrm{~s}, 1 \mathrm{H}, \mathrm{H}-8), 7.50$ $(\mathrm{d}, J=9.1 \mathrm{~Hz}, 1 \mathrm{H}$, pyridine $\mathrm{CH}), 7.70(\mathrm{~s}, 1 \mathrm{H}, \mathrm{H}-5), 7.90-8.00$ (m, 2H, pyridine $\mathrm{CH}), 8.70$ (s, $1 \mathrm{H}, \mathrm{H}-2) ;{ }^{13} \mathrm{C}$ NMR $(101 \mathrm{MHz}$, DMSO- $\left.d_{6}\right) \delta 23.48,42.69,45.32(2 \mathrm{C}), 56.12(2 \mathrm{C}), 50.73(2 \mathrm{C})$, 51.69, 53.25 (2C), 106.18, 107.35, 108.23, 113.45, 114.61, $123.38,132.91,136.12,142.75,145.56,146.42,151.18$, 153.06, 167.45, 176.88. Anal. calcd. for $\mathrm{C}_{26} \mathrm{H}_{33} \mathrm{~N}_{7} \mathrm{O}_{3}: \mathrm{C} 63.52$, H 6.77, N 19.95, found: C 63.79, H 7.02, N 20.13.

\subsubsection{Ethyl 7- Chloro-4-Oxo-1- [2-(4-(Pyridin2-yl) Pipe-} razin-1-yl]) Ethyl] -1,4-Dihydro-1,8- Naphthyridine-3- Carboxylate (40)

The title compound was obtained starting from 37 [32] and [2-(4-(Pyridin2-yl)Piperazin-1-yl])ethyl]amine [33] using Method D $(2 \mathrm{~h})$ to give intermediate 38, followed by Method $\mathrm{E}$ in $56 \%$ overall yield: mp $123-124^{\circ} \mathrm{C}$; ${ }^{1} \mathrm{H}$ NMR $(400 \mathrm{MHz}$, DMSO- $\left.d_{6}\right) \delta 1.30\left(\mathrm{t}, J=7.0 \mathrm{~Hz}, 3 \mathrm{H}, \mathrm{CH}_{2} \mathrm{CH}_{3}\right), 2.45-2.55(\mathrm{~m}$, $4 \mathrm{H}$, piperazine $\left.\mathrm{CH}_{2}\right), 2.75\left(\mathrm{t}, J=6.7 \mathrm{~Hz}, 2 \mathrm{H}, \mathrm{CH}_{2}\right), 3.40-3.50$ (m, $4 \mathrm{H}$, piperazine $\left.\mathrm{CH}_{2}\right), 4.20\left(\mathrm{q}, J=7.0 \mathrm{~Hz}, 2 \mathrm{H}, \mathrm{CH}_{2} \mathrm{CH}_{3}\right)$, $4.60\left(\mathrm{t}, J=6.7 \mathrm{~Hz}, 2 \mathrm{H}, \mathrm{CH}_{2}\right), 6.60-6.65(\mathrm{~m}, 1 \mathrm{H}$, pyridine $\mathrm{CH})$, $6.80(\mathrm{~d}, J=8.7 \mathrm{~Hz}, 1 \mathrm{H}$, pyridine $\mathrm{CH}), 7.50-7.60(\mathrm{~m}, 1 \mathrm{H}$, pyridine $\mathrm{CH}$ ), $7.65(\mathrm{~d}, J=8.3 \mathrm{~Hz}, 1 \mathrm{H}, \mathrm{H}-6), 8.10-8.15(\mathrm{~m}, 1 \mathrm{H}$, pyridine $\mathrm{CH}$ ), 8.60 (d, $J=8.3 \mathrm{~Hz}, 1 \mathrm{H}, \mathrm{H}-5), 8.85$ (s, 1H, H-2).

\subsubsection{Ethyl 7- Chloro-4-Oxo-1- [3-(4-(Pyridin2-yl) Pipe- razin-1-yl]) Propyl]-1,4- Dihydro-1,8- Naphthyridine-3- Carboxylate (41)}

The title compound was obtained starting from 37 [32] and [3-(4-(pyridin-2-yl)piperazin-1-yl)propyl]amine [33] using Method D (2 h) to give intermediate 39, followed by Method E in $59 \%$ overall yield: $\mathrm{mp} 124-125{ }^{\circ} \mathrm{C} ;{ }^{1} \mathrm{H}$ NMR $(400 \mathrm{MHz}$, DMSO- $\left.d_{6}\right) \delta 1.30\left(\mathrm{t}, J=7.0 \mathrm{~Hz}, 3 \mathrm{H}, \mathrm{CH}_{2} \mathrm{CH}_{3}\right), 2.00(\mathrm{t}, J=6.7$ $\left.\mathrm{Hz}, 2 \mathrm{H}, \mathrm{NCH}_{2} \mathrm{CH}_{2}\right), 2.40-2.50\left(\mathrm{~m}, 6 \mathrm{H}, \mathrm{CH}_{2}\right.$ and piperazine $\mathrm{CH}_{2)} 3.40-3.50\left(\mathrm{~m}, 4 \mathrm{H}\right.$, piperazine $\left.\mathrm{CH}_{2}\right), 4.25(\mathrm{q}, J=7.0 \mathrm{~Hz}$, $\left.2 \mathrm{H}, \mathrm{CH}_{2} \mathrm{CH}_{3}\right), 4.50\left(\mathrm{t}, J=6.7 \mathrm{~Hz}, 2 \mathrm{H}, \mathrm{NCH}_{2} \mathrm{CH}_{2}\right), 6.60-6.65$ (m, $1 \mathrm{H}$, pyridine $\mathrm{CH}), 6.80(\mathrm{~d}, J=8.7 \mathrm{~Hz}, 1 \mathrm{H}$, pyridine $\mathrm{CH})$, 7.50-7.60 (m, 1H, pyridine $\mathrm{CH}), 7.65(\mathrm{~d}, J=8.3 \mathrm{~Hz}, 1 \mathrm{H}, \mathrm{H}-6)$, 8.10-8.15 (m, 1H, pyridine $\mathrm{CH}), 8.55$ (d, $J=8.3 \mathrm{~Hz}, 1 \mathrm{H}, \mathrm{H}-5)$, 8.90 (s, 1H, H-2).

\subsubsection{Ethyl 7-[4-(1,3-Benzothiazol-2-Yl)Piperazin-1-Yl]-4- Oxo-1-[2-(4-(Pyridin2-yl)Piperazin-1-yl])Ethyl]-1,4- Dihydro-1,8-Naphthyridine-3-Carboxylate (42)}

The title compound was obtained starting from $\mathbf{4 0}$ and 1(1,3-benzothiazol-2-yl)piperazine [34] using Method A $\left(80^{\circ} \mathrm{C}\right.$, $24 \mathrm{~h})$. After cooling the reaction mixture was poured into ice/water and extracted with $\mathrm{CH}_{2} \mathrm{Cl}_{2}$. The organic layers were evaporated to dryness affording an oil, which was tritured with $\mathrm{Et}_{2} \mathrm{O}$, giving a solid which was filtered, to afford $\mathbf{4 2}$ in $68 \%$ yield: mp $124-125{ }^{\circ} \mathrm{C} ;{ }^{1} \mathrm{H}$ NMR (400 MHz, DMSO- $\left.d_{6}\right) \delta 1.25$ $\left(\mathrm{t}, J=7.0 \mathrm{~Hz}, 3 \mathrm{H}, \mathrm{CH}_{2} \mathrm{CH}_{3}\right), 2.50-2.60(\mathrm{~m}, 4 \mathrm{H}$, piperazine $\left.\mathrm{CH}_{2}\right), 2.75\left(\mathrm{t}, J=6.7 \mathrm{~Hz}, 2 \mathrm{H}, \mathrm{CH}_{2}\right), 3.40-3.50,3.65-3.75$, and 3.80-3.90 (m, each $4 \mathrm{H}$, piperazine $\left.\mathrm{CH}_{2}\right), 4.20(\mathrm{q}, J=7.0 \mathrm{~Hz}$, $\left.2 \mathrm{H}, \mathrm{CH}_{2} \mathrm{CH}_{3}\right), 4.75\left(\mathrm{t}, J=6.7 \mathrm{~Hz}, 2 \mathrm{H}, \mathrm{CH}_{2}\right), 6.60-6.65(\mathrm{~m}, 1 \mathrm{H}$, pyridine $\mathrm{CH}), 6.80(\mathrm{~d}, J=8.7 \mathrm{~Hz}, 1 \mathrm{H}$, pyridine $\mathrm{CH}), 7.00-7.10$ (m, 2H, H-6 and benzothiazole $\mathrm{CH}), 7.25(\mathrm{t}, J=7.4 \mathrm{~Hz}, 1 \mathrm{H}$, benzothiazole $\mathrm{CH}), 7.40-7.50(\mathrm{~m}, 2 \mathrm{H}$, pyridine $\mathrm{CH}$ and benzothiazole $\mathrm{CH}), 7.75(\mathrm{~d}, J=7.9 \mathrm{~Hz}, 1 \mathrm{H}$, benzothiazole $\mathrm{CH}), 8.05-8.10(\mathrm{~m}, 1 \mathrm{H}$, pyridine $\mathrm{CH}), 8.20(\mathrm{~d}, J=8.8 \mathrm{~Hz}$, $\mathrm{H}-5), 8.60$ (s, 1H, H-2).

\subsubsection{Ethyl 7-[4-(1,3-Benzothiazol-2-Yl)Piperazin-1-Yl]-4- Oxo-1-[3-(4-(Pyridin2-yl)Piperazin-1-yl])Propyl]-1,4- Dihydro-1,8-Naphthyridine-3-Carboxylate (43)}

The title compound was obtained starting from 41 and 1(1,3-benzothiazol-2-yl)piperazine [34] using Method A $\left(80{ }^{\circ} \mathrm{C}\right.$, $24 \mathrm{~h}$ ) in $63 \%$ yield: $\mathrm{mp} 140-141{ }^{\circ} \mathrm{C} ;{ }^{1} \mathrm{H}$ NMR (400 MHz, DMSO- $\left.d_{6}\right) \delta 1.30\left(\mathrm{t}, J=7.0 \mathrm{~Hz}, 3 \mathrm{H}, \mathrm{CH}_{2} \mathrm{CH}_{3}\right), 2.00(\mathrm{t}, J=6.7$ $\left.\mathrm{Hz}, 2 \mathrm{H}, \mathrm{NCH}_{2} \mathrm{CH}_{2}\right), 2.40-2.50\left(\mathrm{~m}, 6 \mathrm{H}, \mathrm{CH}_{2}\right.$ and piperazine $\left.\mathrm{CH}_{2}\right), 3.40-3.50,3.65-3.75$ and $3.85-3.95(\mathrm{~m}$, each $4 \mathrm{H}$, piperazine $\left.\mathrm{CH}_{2}\right), 4.20$ (q, $\left.J=7.0 \mathrm{~Hz}, 2 \mathrm{H}, \mathrm{CH}_{2} \mathrm{CH}_{3}\right), 4.40$ (t, $J=$ 6.7 Hz, $\left.2 \mathrm{H}, \mathrm{NCH}_{2} \mathrm{CH}_{2}\right), 6.60-6.65(\mathrm{~m}, 1 \mathrm{H}$, pyridine $\mathrm{CH}), 6.80$ $(\mathrm{d}, J=8.7 \mathrm{~Hz}, 1 \mathrm{H}$, pyridine $\mathrm{CH}), 7.00-7.10(\mathrm{~m}, 2 \mathrm{H}, \mathrm{H}-6$ and benzothiazole $\mathrm{CH}), 7.25(\mathrm{t}, J=7.4 \mathrm{~Hz}, 1 \mathrm{H}$, benzothiazole $\mathrm{CH}$ ), 7.40-7.50 (m, 2H, pyridine $\mathrm{CH}$ and benzothiazole $\mathrm{CH}), 7.75(\mathrm{~d}$, $J=7.9 \mathrm{~Hz}, 1 \mathrm{H}$, benzothiazole $\mathrm{CH}), 8.05-8.10(\mathrm{~m}, 1 \mathrm{H}$, pyridine $\mathrm{CH}), 8.20$ (d, $J=8.8 \mathrm{~Hz}, \mathrm{H}-5), 8.60$ (s, 1H, H-2).

\subsubsection{7-[4-(1,3-Benzothiazol-2-Yl)Piperazin-1-Yl]-4-Oxo-1- [2-(4-(Pyridin-2-Yl)Piperazin-1-Yl)Ethyl]-1,4-Dihydro-1,8- Naphthyridine-3-Carboxylic Acid (11)}

The title compound was obtained starting from 42 using Method C (2 h) after purification by crystallization from DMF in $41 \%$ yield: mp $294-295{ }^{\circ} \mathrm{C}$ (dec.) ${ }^{\circ} \mathrm{C}$; ${ }^{1} \mathrm{H}$ NMR $(400 \mathrm{MHz}$, DMSO- $\left.d_{6}\right) \delta 2.50-2.60\left(\mathrm{~m}, 4 \mathrm{H}\right.$, piperazine $\left.\mathrm{CH}_{2}\right), 2.75(\mathrm{t}, J=6.7$ $\left.\mathrm{Hz}, 2 \mathrm{H}, \mathrm{CH}_{2}\right), 3.30-3.40,3.65-3.75$, and 3.90-4.00 (m, each $4 \mathrm{H}$, piperazine $\left.\mathrm{CH}_{2}\right), 4.65\left(\mathrm{t}, J=6.7 \mathrm{~Hz}, 2 \mathrm{H}, \mathrm{CH}_{2}\right), 6.60-6.65(\mathrm{~m}$, $1 \mathrm{H}$, pyridine $\mathrm{CH}), 6.80(\mathrm{~d}, J=8.7 \mathrm{~Hz}, 1 \mathrm{H}$, pyridine $\mathrm{CH}), 7.05$ (t, $J=7.7 \mathrm{~Hz}, 1 \mathrm{H}$, benzothiazole $\mathrm{CH}$ ), 7.20-7.30 (m, 2H, H-6 and benzothiazole $\mathrm{CH}), 7.40-7.50(\mathrm{~m}, 2 \mathrm{H}$, pyridine $\mathrm{CH}$ and benzothiazole $\mathrm{CH}), 7.75(\mathrm{~d}, J=7.9 \mathrm{~Hz}, 1 \mathrm{H}$, benzothiazole $\mathrm{CH}), 8.05-8.10(\mathrm{~m}, 1 \mathrm{H}$, pyridine $\mathrm{CH}), 8.30(\mathrm{~d}, J=8.8 \mathrm{~Hz}$, $\mathrm{H}-5), 8.80$ (s, 1H, H-2), 15.50 (s, 1H, COOH); ${ }^{13} \mathrm{C}$ NMR (101 MHz, DMSO- $d_{6}$ ) $\delta 44.21$ (2C), 45.27, 47.86 (4C), 52.82 (2C), $56.23,107.61,107.81,108.41,111.50,113.54,119.20,121.75$, $121.88,126.53,130.90,136.42,137.98,147.99,149.62$, $150.01,152.80,159.29,159.46,166.63,168.47,177.04$. Anal. calcd. for $\mathrm{C}_{31} \mathrm{H}_{32} \mathrm{~N}_{8} \mathrm{O}_{3} \mathrm{~S}$ : C $62.40, \mathrm{H} \mathrm{5.41,} \mathrm{N} \mathrm{18.78,} \mathrm{found:} \mathrm{C}$ 62.25, H 5.70, N 18.65 .

\subsubsection{7-[4-(1,3-Benzothiazol-2-Yl)Piperazin-1-Yl]-4-Oxo-1- [3-(4-(Pyridin-2-Yl)Piperazin-1-Yl)Propyl]-1,4-Dihydro-1,8- Naphthyridine-3-Carboxylic Acid (12)}

The title compound was obtained starting from $\mathbf{4 3}$ using Method C (2 h) after purification by crystallization from DMF 
in $16 \%$ yield: $\mathrm{mp} 256-257{ }^{\circ} \mathrm{C}(\mathrm{dec})$; ${ }^{1} \mathrm{H}$ NMR (400 MHz, DMSO- $\left.d_{6}\right) \delta 2.00\left(\mathrm{t}, J=6.7 \mathrm{~Hz}, 2 \mathrm{H}, \mathrm{CH}_{2}\right), 2.25-2.35(\mathrm{~m}, 6 \mathrm{H}$, $\mathrm{CH}_{2}$ and piperazine $\left.\mathrm{CH}_{2}\right), 3.25-3.35,3.65-3.75$ and 3.95-4.00 (m, each $4 \mathrm{H}$, piperazine $\mathrm{CH}_{2}$ ), $4.50\left(\mathrm{t}, J=6.7 \mathrm{~Hz}, 2 \mathrm{H}, \mathrm{CH}_{2}\right.$ ), 6.60-6.65 (m, 1H, pyridine $\mathrm{CH}), 6.75(\mathrm{~d}, J=8.7 \mathrm{~Hz}, 1 \mathrm{H}$, pyridine $\mathrm{CH}), 7.05(\mathrm{t}, J=7.7 \mathrm{~Hz}, 1 \mathrm{H}$, benzothiazole $\mathrm{CH})$, 7.20-7.30 (m, 2H, H-6 and benzothiazole $\mathrm{CH}), 7.40-7.50(\mathrm{~m}$, $2 \mathrm{H}$, pyridine $\mathrm{CH}$ and benzothiazole $\mathrm{CH}), 7.75(\mathrm{~d}, J=7.9 \mathrm{~Hz}$, $1 \mathrm{H}$, benzothiazole $\mathrm{CH}), 8.05-8.10(\mathrm{~m}, 1 \mathrm{H}$, pyridine $\mathrm{CH}), 8.30$ (d, $J=8.8 \mathrm{~Hz}, \mathrm{H}-5), 9.00$ (s, 1H, H-2), 15.50 (s, 1H, COOH); ${ }^{13} \mathrm{C}$ NMR (101 MHz, DMSO- $\left.d_{6}\right) \delta 23.62,42.93,46.48(2 \mathrm{C})$, 48.31 (2C), 49.16 (2C), 51.42, 52.87 (2C), 107.53, 108.16, 108.43, 111.62, 113.48, 119.1, 122.15, 122.88, 126.41, 131.10, $136.72,138.22,148.34,150.21,150.34,152.98,159.75$, 159.88, 166.89, 169.17, 177.25. Anal. calcd. for $\mathrm{C}_{32} \mathrm{H}_{34} \mathrm{~N}_{8} \mathrm{O}_{3} \mathrm{~S}$ : C 62.93, H 5.61, N 18.35, found: C 62.98, H 5.60, N 18.35. .

\subsection{Biology}

\subsubsection{In vitro Anti-HIV Assays}

The evaluation of the antiviral activity of the target compounds against HIV-1 strain $\mathrm{III}_{\mathrm{B}}$ in MT-4 cells was performed using the MTT assay as previously described $[35,36]$. Mock-infected cells were used to assess the cytotoxic effects of the test compounds.

\subsubsection{Fluorescence Quenching Assay (FQA)}

The effect of tested quinolones on the Tat-TAR complex was evaluated using an FQA, a FRET-based competition assay, as previously described [23], using the Tat-derived peptide labelled with the donor fluorescein at its $\mathrm{N}$ terminus and the 29 nt wtTAR labeled at its 3'-end with a dabcyl moiety (quencher).

\section{RESULTS AND DISCUSSION}

\subsection{Chemistry}

The introduction of the guanidine group at C-6 position in the quinolone derivative 1 was accomplished by reacting WM5 [20] with $N, N^{\prime}$-di-(tert-butoxycarbonyl)thiourea in the presence of $\mathrm{HgCl}_{2}$ followed by Boc deprotection of intermediate $\mathbf{1 3}$ under acid conditions Scheme (1).

The synthesis of the C-7 4-carbamimidoylpiperazine derivative 2 started by reacting derivative 14 [28] with methyl imidothiocarbamate sulfate to give intermediate 15 , which, after reduction of the nitro group accomplished with $\mathrm{FeSO}_{4}$ and $\mathrm{NH}_{4} \mathrm{OH}$ followed by acid hydrolysis of the ethyl ester intermediate, led to the target compound 2 Scheme (2).

The C-7 imidazolinpyridinpiperazine derivative $\mathbf{3}$ was synthesized, as outlined in Scheme (3), by reacting intermediate 17 [20] with the 1- [4- (4,5-dihydro-1H-imidazol-2-yl) pyridin-2-yl] piperazine 18 in DMF, affording intermediate 19. Nitro derivative 19 was then catalytically reduced to amino derivative $\mathbf{2 0}$ and finally hydrolysed under basic conditions to give the target compound 3 . The required building block $\mathbf{1 8}$ was in turn prepared through the reaction of nitrile derivative 16 [29] with ethylenediamine in presence of $p$-toluenesulfonic acid.

The synthesis of quinolone derivatives 4 and 6-8 Scheme (4) was accomplished through a cycloaracylation procedure. Thus, acrylate 21 [30] was reacted with (pyridin-2-ylmethyl) amine, (3-bromopropyl) amine, and $\mathrm{N}$-(pyridin-2-yl) propane-1,3-diamine in $\mathrm{Et}_{2} \mathrm{O} / \mathrm{EtOH}$ mixture at room temperature to give intermediates 22-24, which by treatment with $\mathrm{K}_{2} \mathrm{CO}_{3}$ in dry DMF at $80{ }^{\circ} \mathrm{C}$ afforded synthons $\mathbf{2 5 - 2 7}$. These derivatives were then subjected to nucleophilic reaction with 1-(2pyridinyl) piperazine in dry DMF, to give intermediates 28-31. In the case of compound 26, the nucleophilic reaction led to the mixture of the di-substituted $\mathbf{2 9}$ and mono-substituted 30, which were easily isolated by chromatographical purification. Intermediate 30 was then functionalized at the $\mathrm{N}-1$ position by reaction with piperazine in presence of DIPEA in dry DMF affording derivative 32. Then, the 6-nitro-derivatives $\mathbf{2 8 ,} \mathbf{2 9}$, 31 , and 32 were catalytically reduced to give 6 -amino-derivatives 33-36. Finally, the target compounds 4 and 6-8 were obtained by saponification of the corresponding ethyl esters 33-36.

By following an analogous synthetic route, 1,8-naphthyridone derivatives $\mathbf{1 1}$ and $\mathbf{1 2}$ were prepared as presented in Scheme (5). Thus, the reaction of acrylate 37 [32] with [2-(4(pyridin-2-yl)piperazin-1-yl)ethyl]amine [33] and [3-(4(pyridin-2-yl)piperazin-1-yl)propyl]amine [33] in $\mathrm{Et}_{2} \mathrm{O} / \mathrm{EtOH}$ mixture at room temperature gave intermediates $\mathbf{3 8}$ and $\mathbf{3 9}$, which by treatment with $\mathrm{K}_{2} \mathrm{CO}_{3}$ in dry DMF at $80^{\circ} \mathrm{C}$, afforded synthons $\mathbf{4 0}$ and $\mathbf{4 1}$, respectively. The nucleophilic reaction of naphthyridone derivatives $\mathbf{4 0}$ and $\mathbf{4 1}$ with 1 - (1,3- benzothiazol-2-yl) piperazine [34] led to intermediates $\mathbf{4 2}$ and $\mathbf{4 3}$. Finally, the target compounds $\mathbf{1 1}$ and $\mathbf{1 2}$ were obtained by saponification of the corresponding ethyl esters $\mathbf{4 2}$ and $\mathbf{4 3}$.

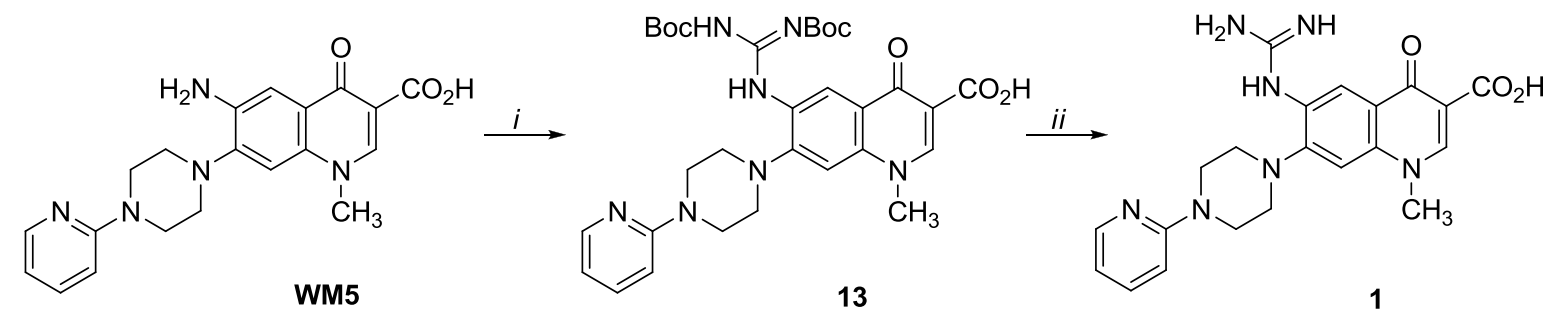

Scheme 1. Reagents and conditions: (i) N,N'-di-(tert-butoxycarbonyl)thiourea, $\mathrm{HgCl}_{2}, \mathrm{Et}_{3} \mathrm{~N}$, dry DMF, rt; (ii) $\mathrm{HCl} \mathrm{g,} \mathrm{CHCl}_{3}$, EtOH, rt. 
<smiles>CCOC(=O)c1cn(C)c2cc(N3CCN(C(=N)N)CC3)c([N+](=O)[O-])cc2c1=O</smiles>

Scheme 2. Reagents and conditions: (i) methyl imidothiocarbamate sulfate, dry DMSO, $120{ }^{\circ} \mathrm{C}$; (ii) $\mathrm{FeSO}_{4} \cdot 7 \mathrm{H}_{2} \mathrm{O}, \mathrm{NH}_{4} \mathrm{OH}, \mathrm{H}_{2} \mathrm{O}$, rt; (iii) $6 \mathrm{~N} \mathrm{HCl}$, EtOH, reflux.<smiles>[R]c1cc2c(=O)c(C(=O)OCC)cn(C)c2cc1N1CCN(c2cc(C3=NCCN3)ccn2)CC1</smiles>

Scheme 3. Reagents and conditions: (i) ethylenediamine, $p$-toluenesulfonic acid, reflux; (ii) dry DMF, $\mathrm{K}_{2} \mathrm{CO}_{3}, 80{ }^{\circ} \mathrm{C}$; (iii) $\mathrm{H}_{2}$, Raney $\mathrm{Ni}$, DMF rt; (iv) $4 \% \mathrm{NaOH}$, reflux.<smiles>CCOC(=O)C(=CN(C)C)C(=O)c1cc([N+](=O)[O-])c(Cl)cc1Cl</smiles>

21<smiles>[R]N/C=C(\C(=O)OCC)C(=O)c1cc([N+](=O)[O-])c(Cl)cc1Cl</smiles>

$22 \mathrm{R}_{1}=-\mathrm{CH}_{2}-\mathrm{Pyr}$

$23 \mathrm{R}_{1}=-\left(\mathrm{CH}_{2}\right)_{3}-\mathrm{Br}$

$24 \mathrm{R}_{1}=-\left(\mathrm{CH}_{2}\right)_{3}-\mathrm{NH}-\mathrm{Pyr}$<smiles>[R1]n1cc(C(=O)OCC)c(=O)c2cc([N+](=O)[O-])c(Cl)cc21</smiles>

$25 \mathrm{R}_{1}=-\mathrm{CH}_{2}-\mathrm{Pyr}$

$26 \mathrm{R}_{1}=-\left(\mathrm{CH}_{2}\right)_{3}-\mathrm{Br}$

$27 \mathrm{R}_{1}=-\left(\mathrm{CH}_{2}\right)_{3}-\mathrm{NH}-\mathrm{Pyr}$

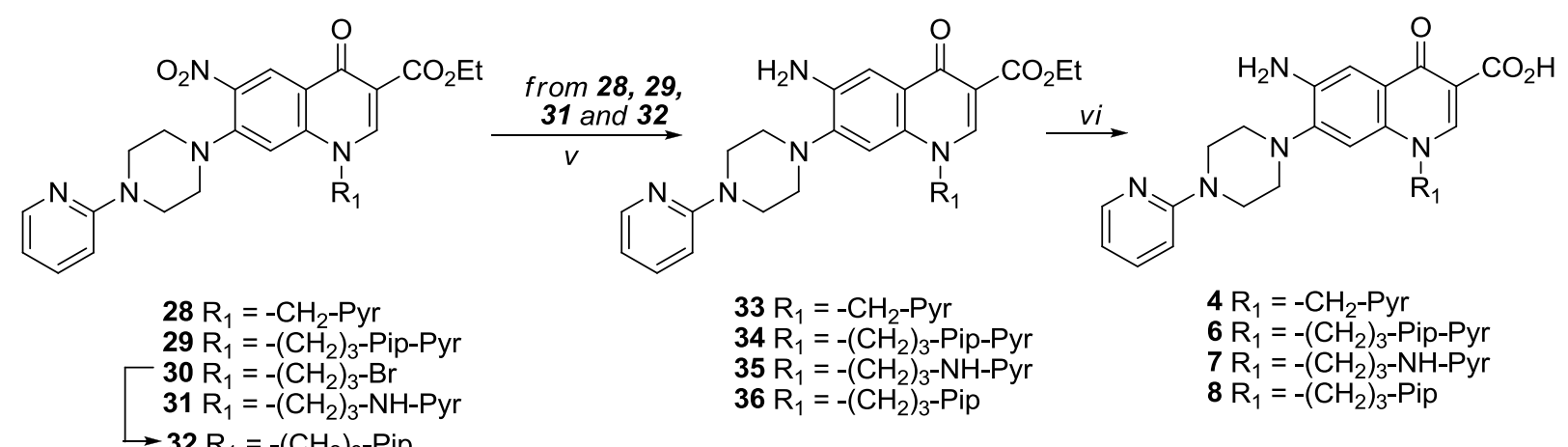

Scheme 4. Reagents and conditions: (i) (pyridin-2-ylmethyl)amine, (3-bromopropyl)amine, or $N$-(pyridin-2-yl)propane-1,3-diamine, $\mathrm{Et}_{2} \mathrm{O} / \mathrm{EtOH}$ (3:1)rt; (ii) $\mathrm{K}_{2} \mathrm{CO}_{3}$, dry DMF rt, $80^{\circ} \mathrm{C}$; (iii) 1-(2-pyridinyl)piperazine, dry DMF, $\mathrm{K}_{2} \mathrm{CO}_{3}, 80^{\circ} \mathrm{C}$; (iv) piperazine, DIPEA, dry DMF, $80^{\circ} \mathrm{C}$; (v) $\mathrm{H}_{2}$, Raney Ni, DMF; (vi) $4 \% \mathrm{NaOH}$, reflux. 
<smiles>[R7]N/C=C(/C(=O)OCC)C(=O)c1ccc(Cl)nc1Cl</smiles>

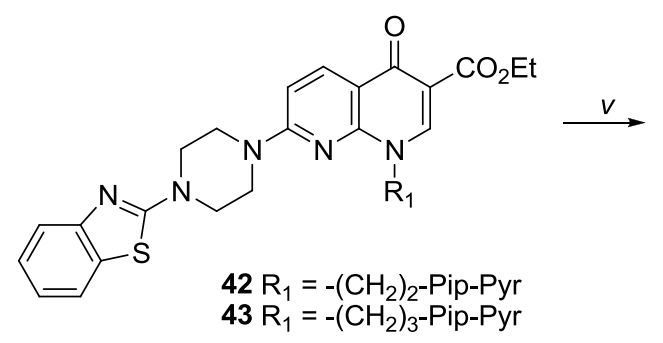

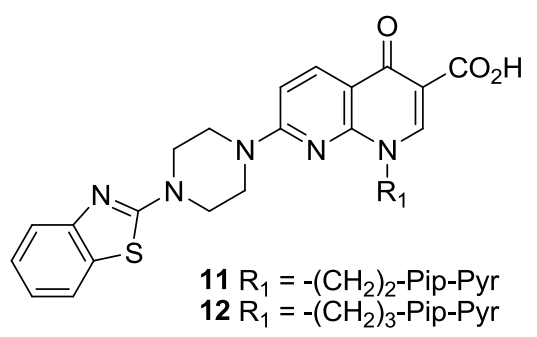

Scheme 5. Reagents and conditions: (i) [2-(4-(pyridin-2-yl)piperazin-1-yl)ethyl]amine, [3-(4-(pyridin-2-yl)piperazin-1-yl)propyl]amine, Et ${ }_{2} \mathrm{O} / \mathrm{EtOH}$ (3:1), rt; (ii) $\mathrm{K}_{2} \mathrm{CO}_{3}$, dry DMF, $80^{\circ} \mathrm{C}$; (iii) 1-(1,3-benzothiazol-2-yl)piperazine, $\mathrm{K}_{2} \mathrm{CO}_{3}$, dry DMF, $80^{\circ} \mathrm{C}$; (iv) $\mathrm{H}_{2}$, Raney $\mathrm{Ni}$, DMF rt; (v) $4 \% \mathrm{NaOH}$, reflux.

Table 1. Anti-HIV-1 activity and cytotoxicity of quinolones in MT-4 cells and inhibition of Tat-TAR complex formation.

\begin{tabular}{|c|c|c|c|c|}
\hline Compd & $\begin{array}{l}\mathrm{EC}_{50}(\mu \mathrm{M})^{a, c} \\
\text { HIV-1 }\left(\mathrm{III}_{\mathrm{B}}\right)\end{array}$ & $\mathrm{CC}_{50}(\mu \mathrm{M})^{b, c}$ & $\mathbf{S I}^{d}$ & Ki Tat-TAR $(\boldsymbol{\mu M})^{e}$ \\
\hline 1 & $>296$ & $>296$ & 1 & N.T. ${ }^{f}$ \\
\hline 2 & $>363$ & 363 & 1 & N.T. \\
\hline 3 & $>34.9$ & $34.9 \pm 1.43$ & $<1$ & N.T. \\
\hline 4 & $>19.8$ & $19.8 \pm 5.02$ & $<1$ & N.T. \\
\hline $5^{g}$ & $5.05 \pm 0.41$ & $20.9 \pm 3.93$ & 4 & $1.15 \pm 0.55$ \\
\hline 6 & $1.21 \pm 0.08$ & $5.92 \pm 2.19$ & 5 & $0.91 \pm 0.27$ \\
\hline 7 & $\geq 3.42$ & $3.94 \pm 0.62$ & $\leq 1$ & $2.18 \pm 0.40$ \\
\hline 8 & $70.8 \pm 0.71$ & $>254$ & $>4$ & N.T. \\
\hline $9^{g}$ & $1.16 \pm 0.18$ & $3.97 \pm 0.70$ & 3 & N.D. ${ }^{h}$ \\
\hline $10^{g}$ & $\geq 0.18$ & $3.34 \pm 1.47$ & $\leq 18$ & $1.72 \pm 0.22$ \\
\hline 11 & $3.37 \pm 1.62$ & $11.65 \pm 1.17$ & 3.5 & N.D. \\
\hline 12 & $\geq 0.67$ & $10.70 \pm 7.76$ & $\leq 16$ & N.D. \\
\hline WM5 $^{i}$ & $0.15 \pm 0.05$ & $2.21 \pm 1.05$ & 15 & $2.22 \pm 0.66$ \\
\hline
\end{tabular}

${ }^{a} \mathrm{EC}_{50}$ : concentration of compound required to achieve $50 \%$ protection of MT-4 cells from HIV-1 induced cytopathogenicity, as determined by the MTT method. ${ }^{b} \mathrm{CC}_{50}$ : concentration of compound that reduces the viability of mock-infected cells by $50 \%$, as determined by the MTT method. ${ }^{c}$ All data represent mean values \pm standard deviations for three separate experiments. ${ }^{d} \mathrm{SI}$ : ratio of $\mathrm{CC}_{50} / \mathrm{EC}_{50} \cdot{ }^{e} \mathrm{Ki}$ from FQA experiments performed with 10 aa FAM-Tat peptide in Tris $10 \mathrm{mM}$, $\mathrm{pH} 7.5, \mathrm{Mg}(\mathrm{ClO})_{2} 1$ $\mathrm{mM}, \mathrm{NaCl} 20 \mathrm{mM}$ (TNMg), 0.01\% Triton X-100. ${ }^{f}$ N.T.: not tested. ${ }^{g}$ Reference [25]. ${ }^{h}$ N.D.: not determined due to solubility issue. ${ }^{i}$ Reference [20].

\subsection{Biological Evaluation}

The newly synthesized compounds were initially evaluated for anti-HIV-1 ( $\left.\mathrm{III}_{\mathrm{B}}\right)$ activity in MT-4 cells, determining their cytotoxicity in parallel Table 1. WM5 [20] was evaluated in the same cell lines for comparative purposes.

From the results, it emerged that the introduction of a C-6 guanidine group (compound $\mathbf{1}$ ) as well as an amidine moiety and a 4-imidazolinpyridine ring at the C-7 position (compounds $\mathbf{2}$ and $\mathbf{3}$ ) was completely detrimental in the inhibition of HIV replication. However, the low cytotoxicity showed by the compounds could suggest their inability to enter the cells.
The introduction of a 2-pyridinylmethyl moiety at N-1 position (compound 4) did not produce an active derivative $\left(\mathrm{EC}_{50}>19.8 \mu \mathrm{M}\right)$. Conversely, the presence of a (pyridin-2-yl) piperazine spaced by an ethylene or propylene unit permitted to restore the anti-HIV-1 activity in compounds 5 and $\mathbf{6}\left(\mathrm{EC}_{50}=\right.$ 5.05 and $1.21 \mu \mathrm{M}$, respectively) at no cytotoxic concentrations.

By alternatively deleting the piperazine or pyridine ring in compound 6, no activity at subcytotoxic concentrations was observed for compound 7 , while only a weak inhibitory activity was conserved by compound $\mathbf{8}$. More interesting results were achieved when protonable side chains were inserted at the N-1 position of the 1,8-naphthyridone scaffold. In particular, the 
introduction of the (pyridin-2-yl)piperazine spaced by an ethylene or propylene unit gave compounds $\mathbf{1 1}$ and 12, both endowed with good anti-HIV-1 activity $\left(\mathrm{EC}_{50}=3.37\right.$ and $\geq 0.67$ $\mu \mathrm{M})$ coupled with SI values of 3.5 and $\leq 16$, respectively. The deletion of the piperazine ring, as in compound $\mathbf{9}$ and $\mathbf{1 0}$, also in this case permitted to maintain anti-HIV-1 $\left(\mathrm{EC}_{50}=1.16\right.$ and $\geq 0.18 \mu \mathrm{M}, \mathrm{SI}=3$ and $\leq 18$, respectively), with compound $\mathbf{1 0}$ that emerged as the most potent of the series.

In order to investigate the ability of active anti-HIV-1 compounds (derivative 5-7 and 9-12) to interfere with the formation of the Tat-TAR complex, they were evaluated in a FQA using a truncated Tat peptide. Unfortunately, solubility issues did not allow the evaluation of compounds 9, 11 and $\mathbf{1 2}$. Derivatives 5, 6, and 10 appeared to be able to inhibit the TatTAR complex formation, all presenting $\mathrm{Ki}$ values even improved as compared to the values obtained with WM5 Table 1. In particular, enhancing the distance of the pyridine ring from the quinolone nucleus, the ability of the compounds to inhibit the formation of the complex peptide-TAR increases: Ki $\mathbf{6}<\mathbf{5}<\mathbf{7}$; moreover, the presence of a piperazine in the side chain (compounds $\mathbf{6}$ and $\mathbf{5}$ ) has a positive effect on the activity of compounds, probably because it confers more rigidity to the chain and the position of the pyridine ring respect to the quinolone nucleus is fixed. Even if a strict correlation between the $\mathrm{Ki}$ values and the anti-HIV activities did not exist, this assay confirmed that the impairment of the Tat-TAR complex formation represents a putative target for the new derivatives.

\section{CONCLUSION}

The Tat-mediated transcription, the only phase of the HIV-1 replicative cycle in which viral genome amplification occurs, is a really attractive step that if inhibited by a suitable inhibitor could lead to a functional cure or even HIV infection eradication. For years, the inhibition of the Tat-mediated transcription has been highly pursued through different approaches, but this step of the viral replicative cycle remains untouched by any of the drugs in therapy. However, there are examples of promising Tat-mediated transcription inhibitors worthy to be mentioned, such as triptolide [37] and dCA [38] working on Tat protein.

In the attempt to obtain potent TAR binders, we started from WM5, a small molecule endowed with potent anti-HIV and Tat-mediated transcription inhibition activity thanks to the ability to selectively bind the bulge region of TAR; indeed no interaction with TAR-unrelated nucleic acids such as tRNA sequence and single-stranded or double-stranded DNA structures was observed [39].

Starting from WM5, various protonable moieties were inserted in different positions of the quinolone scaffold, intended to mime the basic region of Tat involved in the TAR interaction. The modifications introduced in the structure do not result in loss of activity, but rather seem to improve the activity as inhibitors of the Tat-TAR complex formation, leading to the identification of compounds able to recognize TAR better than WM5. Important SAR insights were also achieved for the quinolone class of anti-HIV derivatives. In particular, the C-6 and C-7 positions were confirmed as particularly sensitive to structural modifications, while the N-1 emerged as a suitable position to host protonable moieties such as the pyridine-based side chains. This is an important new insight since the most potent quinolones reported until now were all characterized by the presence of small alkyl groups at the $\mathrm{N}-1$ position $[22,40]$. In addition, potent anti-HIV compounds were identified, with naphthyridone derivatives $\mathbf{1 0}$ and 12 which showed $\mathrm{EC}_{50}$ values in the sub-micromolar range.

In conclusion, the addition of protonable chains as tool to improve the TAR binding properties permitted to obtain active compounds, but additional knowledge on the interaction of TAR RNA with viral protein Tat and host Super Elongation Complex (SEC) [41, 42] are still necessary to design compounds able to better recognize the TAR RNA and potently inhibit HIV replication. During the reviewing of this work, two interesting papers were published that could help the design of an effective TAR binder. In particular, SchulzeGahmen and Hurley solved the crystal structure of the TAR in complex with Tat and the SEC core (CycT1/CDK9/AFF4) [43], while Varani and co-workers reported the NMR structure of TAR RNA in complex with a ultra-potent macrocyclic peptide that mimics the Arginine Rich Motif (ARM) of Tat [44], which however only weakly inhibit the Tat-mediated transcription.

These studies revealed how the direct interaction of TatARM with TAR RNA bulge is required to induce the RNA structural change, but it is the recognition of the loop by the CycT1 that dominantly contributes to the binding energy. Thus, a future TAR binder should be able to target not only the UCU bulge but above all the interaction of CycT1 with the rearranged TAR RNA loop, to achieve an effective Tatmediated transcription inhibition in cells.

\section{LIST OF ABBREVIATIONS}

ARM $=$ Arginine Rich Motif
SAR $=$ Structure-Activity Relationship
SEC $=$ Super Elongation Complex
TAR $=$ Transactivation Response Element
FQA $=$ Fluorescence Quenching Assay.
ETHICS APPROVAL AND CONSENT TO PARTI-
CIPATE

Not applicable

\section{HUMAN AND ANIMAL RIGHTS}

No Animals/Humans were used for studies that are basis of this research.

\section{CONSENT FOR PUBLICATION}

Not applicable

\section{CONFLICT OF INTEREST}

The authors declare no conflict of interest, financial, or otherwise.

\section{ACKNOWLEDGEMENTS}

We thank K. Erven, K. Uyttersprot and C. Heens for 
technical assistance with the evaluation of the anti-HIV activity and the assessment of cytotoxicity.

\section{REFERENCES}

[1] Thomas, J.R.; Hergenrother, P.J. Targeting RNA with small molecules. Chem. Rev., 2008, 108(4), 1171-1224.

[http://dx.doi.org/10.1021/cr0681546] [PMID: 18361529]

[2] Hermann, T. Small molecules targeting viral RNA. Wiley Interdiscip. Rev. RNA, 2016, 7(6), 726-743.

[http://dx.doi.org/10.1002/wrna.1373] [PMID: 27307213]

[3] Kolář, M.H.; Tabarrini, O. Halogen Bonding in Nucleic Acid Complexes. J. Med. Chem., 2017, 60(21), 8681-8690. [http://dx.doi.org/10.1021/acs.jmedchem.7b00329] [PMID: 28605588]

[4] Weeks, K.M.; Ampe, C.; Schultz, S.C.; Steitz, T.A.; Crothers, D.M. Fragments of the HIV-1 Tat protein specifically bind TAR RNA. Science, 1990, 249(4974), 1281-1285.

[http://dx.doi.org/10.1126/science.2205002] [PMID: 2205002]

[5] Aboul-ela, F.; Karn, J.; Varani, G. Structure of HIV-1 TAR RNA in the absence of ligands reveals a novel conformation of the trinucleotide bulge. Nucleic Acids Res., 1996, 24(20), 3974-3981. [http://dx.doi.org/10.1093/nar/24.20.3974] [PMID: 8918800]

[6] Dethoff, E.A.; Petzold, K.; Chugh, J.; Casiano-Negroni, A.; AlHashimi, H.M. Visualizing transient low-populated structures of RNA. Nature, 2012, 491(7426), 724-728.

[http://dx.doi.org/10.1038/nature11498] [PMID: 23041928]

[7] Puglisi, J.D.; Chen, L.; Frankel, A.D.; Williamson, J.R. Role of RNA structure in arginine recognition of TAR RNA. Proc. Natl. Acad. Sci. USA, 1993, 90(8), 3680-3684.

[http://dx.doi.org/10.1073/pnas.90.8.3680] [PMID: 7682716]

[8] Tao, J.; Chen, L.; Frankel, A.D. Dissection of the proposed base triple in human immunodeficiency virus TAR RNA indicates the importance of the Hoogsteen interaction. Biochemistry, 1997, 36(12), 3491-3495. [http://dx.doi.org/10.1021/bi962259t] [PMID: 9131998]

[9] Huthoff, H.; Girard, F.; Wijmenga, S.S.; Berkhout, B. Evidence for a base triple in the free HIV-1 TAR RNA. RNA, 2004, 10(3), 412-423. [http://dx.doi.org/10.1261/rna.5161304] [PMID: 14970387]

[10] Mousseau, G.; Valente, S.T. Role of host factors on the regulation of Tat-Mediated HIV-1 transcription. Curr. Pharm. Des., 2017, 23(28), 4079-4090.

[http://dx.doi.org/10.2174/1381612823666170622104355] [PMID: 28641539]

[11] Schiralli Lester, G.M.; Henderson, A.J. Mechanisms of HIV transcriptional regulation and their contribution to latency. Mol. Biol. Int., 2012, 2012, 614120 .

[http://dx.doi.org/10.1155/2012/614120] [PMID: 22701796]

[12] Massari, S.; Sabatini, S.; Tabarrini, O. Blocking HIV-1 replication by targeting the Tat-hijacked transcriptional machinery. Curr. Pharm. Des., 2013, 19(10), 1860-1879.

[http://dx.doi.org/10.2174/1381612811319100010] [PMID: 23092279]

[13] Tabarrini, O.; Desantis, J.; Massari, S. Recent advances in the identification of Tat-mediated transactivation inhibitors: progressing toward a functional cure of HIV. Future Med. Chem., 2016, 8(4), 421-442.

[http://dx.doi.org/10.4155/fmc.16.3] [PMID: 26933891]

[14] Abulwerdi, F.A.; Le Grice, S.F.J. Recent advances in targeting the HIV-1 Tat/TAR complex. Curr. Pharm. Des., 2017, 23(28), 4112-4121.

[http://dx.doi.org/10.2174/1381612823666170616081736] [PMID: 28625133]

[15] Hamy, F.; Felder, E.R.; Heizmann, G.; Lazdins, J.; Aboul-ela, F.; Varani, G.; Karn, J.; Klimkait, T. An inhibitor of the Tat/TAR RNA interaction that effectively suppresses HIV-1 replication. Proc. Natl. Acad. Sci. USA, 1997, 94(8), 3548-3553.

[http://dx.doi.org/10.1073/pnas.94.8.3548] [PMID: 9108013]

[16] Abulwerdi, F.A.; Shortridge, M.D.; Sztuba-Solinska, J.; Wilson, R.; Le Grice, S.F.; Varani, G.; Schneekloth, J.S., Jr. Development of small molecules with a noncanonical binding mode to HIV-1 trans activation response (TAR) RNA. J. Med. Chem., 2016, 59(24), 11148-11160. [http://dx.doi.org/10.1021/acs.jmedchem.6b01450] [PMID: 28002966]

[17] Davidson, A.; Begley, D.W.; Lau, C.; Varani, G. A small-molecule probe induces a conformation in HIV TAR RNA capable of binding drug-like fragments. J. Mol. Biol., 2011, 410(5), 984-996.

[http://dx.doi.org/10.1016/j.jmb.2011.03.039] [PMID: 21763501]

[18] Davidson, A.; Leeper, T.C.; Athanassiou, Z.; Patora-Komisarska, K.; Karn, J.; Robinson, J.A.; Varani, G. Simultaneous recognition of
HIV-1 TAR RNA bulge and loop sequences by cyclic peptide mimics of Tat protein. Proc. Natl. Acad. Sci. USA, 2009, 106(29), 11931-11936.

[http://dx.doi.org/10.1073/pnas.0900629106] [PMID: 19584251]

[19] Sztuba-Solinska, J.; Shenoy, S.R.; Gareiss, P.; Krumpe, L.R.; Le Grice, S.F.; O'Keefe, B.R.; Schneekloth, J.S., Jr Identification of biologically active, HIV TAR RNA-binding small molecules using small molecule microarrays. J. Am. Chem. Soc., 2014, 136(23), $8402-8410$.

[http://dx.doi.org/10.1021/ja502754f] [PMID: 24820959]

[20] Cecchetti, V.; Parolin, C.; Moro, S.; Pecere, T.; Filipponi, E.; Calistri, A.; Tabarrini, O.; Gatto, B.; Palumbo, M.; Fravolini, A.; Palù', G. 6Aminoquinolones as new potential anti-HIV agents. J. Med. Chem., 2000, 43(20), 3799-3802.

[http://dx.doi.org/10.1021/jm9903390] [PMID: 11020296]

[21] Tabarrini, O.; Massari, S.; Cecchetti, V. 6-desfluoroquinolones as HIV-1 Tat-mediated transcription inhibitors. Future Med. Chem., 2010, 2(7), 1161-1180.

[http://dx.doi.org/10.4155/fmc.10.208] [PMID: 21426162]

[22] Tabarrini, O.; Massari, S.; Daelemans, D.; Meschini, F.; Manfroni, G.; Bottega, L.; Gatto, B.; Palumbo, M.; Pannecouque, C.; Cecchetti, V. Studies of anti-HIV transcription inhibitor quinolones: identification of potent N1-vinyl derivatives. Chem Med Chem, 2010, 5(11), 1880-1892.

[http://dx.doi.org/10.1002/cmdc.201000267] [PMID: 20928882]

[23] Manfroni, G.; Gatto, B.; Tabarrini, O.; Sabatini, S.; Cecchetti, V.; Giaretta, G.; Parolin, C.; Del Vecchio, C.; Calistri, A.; Palumbo, M.; Fravolini, A. Synthesis and biological evaluation of 2phenylquinolones targeted at Tat/TAR recognition. Bioorg. Med. Chem. Lett., 2009, 19(3), 714-717. [http://dx.doi.org/10.1016/j.bmcl.2008.12.034] [PMID: 19109014]

[24] Gatto, B.; Tabarrini, O.; Massari, S.; Giaretta, G.; Sabatini, S.; Del Vecchio, C.; Parolin, C.; Fravolini, A.; Palumbo, M.; Cecchetti, V. 2Phenylquinolones as inhibitors of the HIV-1 Tat-TAR interaction. ChemMedChem, 2009, 4(6), 935-938.

[http://dx.doi.org/10.1002/cmdc.200800437] [PMID: 19283692]

[25] Donalisio, M.; Massari, S.; Argenziano, M.; Manfroni, G.; Cagno, V.; Civra, A.; Sabatini, S.; Cecchetti, V.; Loregian, A.; Cavalli, R.; Lembo, D.; Tabarrini, O. Ethyl 1,8-naphthyridone-3-carboxylates downregulate human papillomavirus-16 E6 and E7 oncogene expression. J. Med. Chem., 2014, 57(13), 5649-5663. [http://dx.doi.org/10.1021/jm500340h] [PMID: 24905115]

[26] Massari, S.; Daelemans, D.; Barreca, M.L.; Knezevich, A.; Sabatini, S.; Cecchetti, V.; Marcello, A.; Pannecouque, C.; Tabarrini, O. A 1,8naphthyridone derivative targets the HIV-1 Tat-mediated transcription and potently inhibits the HIV-1 replication. J. Med. Chem., 2010, 53(2), 641-648.

[http://dx.doi.org/10.1021/jm901211d] [PMID: 19958026]

[27] Tabarrini, O.; Massari, S.; Sancineto, L.; Daelemans, D.; Sabatini, S.; Manfroni, G.; Cecchetti, V.; Pannecouque, C. Structural investigation of the naphthyridone scaffold: identification of a 1,6-naphthyridone derivative with potent and selective anti-HIV activity. Chem Med Chem, 2011, 6(7), 1249-1257.

[http://dx.doi.org/10.1002/cmdc.201100073] [PMID: 21567967]

[28] Tabarrini, O.; Massari, S.; Daelemans, D.; Stevens, M.; Manfroni, G.; Sabatini, S.; Balzarini, J.; Cecchetti, V.; Pannecouque, C.; Fravolini, A. Structure-activity relationship study on anti-HIV 6-desfluoroquinolones. J. Med. Chem., 2008, 51(17), 5454-5458.

[http://dx.doi.org/10.1021/jm701585h] [PMID: 18710207]

[29] Cecchetti, V.; Clementi, S.; Cruciani, G.; Fravolini, A.; Pagella, P. G.; Savino, A.; Tabarrini, O. 6-Aminoquinolones: A new class of quinolone antibacterials? J. Med. Chem., 1995, 38(6), 973-982.

[30] Anderson, D.; Beutel, B.; Bosse, T. D.; Clark, R.; Cooper, C.; Dandliker, P.; David, C.; Yu-Gui, H.; Todd, M.; Hinman, M.; Kalvin, D.; Larson, D. P.; Lynch, L.; Ma, Z.; Motter, C.; Palazzo, F.; Rosenberg, T.; Rehm, T.; Sanders, W.; Tufano, M.; Wagner, R.; Weitzberg, M.; Yong, H.; Zhang, T. Preparation of naphthyridines as antibacterial compounds. US200 32328182003.

[31] Elliott, R. L.; Hammond, M.; Hank, R. F. 2-Pyridyl-4-heteroarylimidazoles for the treatment of obesity. WO006 6578(A1), 2000

[32] Ife, R.J.; Catchpole, K.W.; Durant, G.J.; Robin Ganellin, C.; Harvey, C.A.; Meeson, M.L.; Owen, D.A. Parsons, M. E.; Slingsby, B. P.; Theobald, C. J. Non-Basic Histamine H1-Antagonists. I. Synthesis and Biological Evaluation of Some Substituted 2-(2-Pyridylaminoalkylamino) Pyrimidones and Related Compounds. Eur. J. Med. Chem., 1989, 24(3), 249-257. [http://dx.doi.org/10.1016/0223-5234(89)90006-8] 
[33] Jung, H.K.; Doddareddy, M.R.; Cha, J.H.; Rhim, H.; Cho, Y.S.; Koh, H.Y.; Jung, B.Y.; Pae, A.N. Synthesis and biological evaluation of novel T-type Ca2+ channel blockers. Bioorg. Med. Chem., 2004, 12(15), 3965-3970.

[http://dx.doi.org/10.1016/j.bmc.2004.06.011] [PMID: 15246072]

[34] Verderame, M. 1,4-Disubstituted piperazines. 3. Piperazinylbenzothiazoles. J. Med. Chem., 1972, 15(6), 693-694.

[http://dx.doi.org/10.1021/jm00276a039] [PMID: 4555494]

[35] Pannecouque, C.; Daelemans, D.; De Clercq, E. Tetrazolium-based colorimetric assay for the detection of HIV replication inhibitors: revisited 20 years later. Nat. Protoc., 2008, 3(3), 427-434. [http://dx.doi.org/10.1038/nprot.2007.517] [PMID: 18323814]

[36] Pauwels, R.; Balzarini, J.; Baba, M.; Snoeck, R.; Schols, D.; Herdewijn, P.; Desmyter, J.; De Clercq, E. Rapid and automated tetrazolium-based colorimetric assay for the detection of anti-HIV compounds. J. Virol. Methods, 1988, 20(4), 309-321.

[http://dx.doi.org/10.1016/0166-0934(88)90134-6] [PMID: 2460479]

[37] Wan, Z.; Chen, X. Triptolide inhibits human immunodeficiency virus type 1 replication by promoting proteasomal degradation of Tat protein. Retrovirology, 2014, 11,88.

[http://dx.doi.org/10.1186/s12977-014-0088-6] [PMID: 25323821]

[38] Mousseau, G.; Clementz, M.A.; Bakeman, W.N.; Nagarsheth, N.; Cameron, M.; Shi, J.; Baran, P.; Fromentin, R.; Chomont, N.; Valente, S.T. An analog of the natural steroidal alkaloid cortistatin A potently suppresses Tat-dependent HIV transcription. Cell Host Microbe, 2012, 12(1), 97-108

[http://dx.doi.org/10.1016/j.chom.2012.05.016] [PMID: 22817991]
[39] Richter, S.N.; Gatto, B.; Tabarrini, O.; Fravolini, A.; Palumbo, M. Antiviral 6-amino-quinolones: molecular basis for potency and selectivity. Bioorg. Med. Chem. Lett., 2005, 15(19), 4247-4251. [http://dx.doi.org/10.1016/j.bmcl.2005.06.074] [PMID: 16054362]

[40] Massari, S.; Daelemans, D.; Manfroni, G.; Sabatini, S.; Tabarrini, O.; Pannecouque, C.; Cecchetti, V. Studies on anti-HIV quinolones: new insights on the C-6 position. Bioorg. Med. Chem., 2009, 17(2), 667-674.

[http://dx.doi.org/10.1016/j.bmc.2008.11.056] [PMID: 19091580]

[41] Schulze-Gahmen, U.; Echeverria, I.; Stjepanovic, G.; Bai, Y.; Lu, H.; Schneidman-Duhovny, D.; Doudna, J.A.; Zhou, Q.; Sali, A.; Hurley, J.H. Insights into HIV-1 proviral transcription from integrative structure and dynamics of the Tat:AFF4:P-TEFb:TAR complex. eLife, 2016, 5, e15910.

[http://dx.doi.org/10.7554/eLife.15910] [PMID: 27731797]

[42] Gu, J.; Babayeva, N.D.; Suwa, Y.; Baranovskiy, A.G.; Price, D.H.; Tahirov, T.H. Crystal structure of HIV-1 Tat complexed with human P-TEFb and AFF4. Cell Cycle, 2014, 13(11), 1788-1797. [http://dx.doi.org/10.4161/cc.28756] [PMID: 24727379]

[43] Schulze-Gahmen, U.; Hurley, J.H. Structural mechanism for HIV-1 TAR loop recognition by Tat and the super elongation complex. Proc. Natl. Acad. Sci. USA, 2018, 115(51), 12973-12978.

[http://dx.doi.org/10.1073/pnas.1806438115] [PMID: 30514815]

[44] Shortridge, M.D.; Wille, P.T.; Jones, A.N.; Davidson, A.; Bogdanovic, J.; Arts, E.; Karn, J.; Robinson, J.A.; Varani, G. An ultra-high affinity ligand of HIV-1 TAR reveals the RNA structure recognized by PTEFb. Nucleic Acids Res., 2018. [http://dx.doi.org/10.1093/nar/gky1197] [PMID: 30481318]

(C) 2019 Desantis et al.

This is an open access article distributed under the terms of the Creative Commons Attribution 4.0 International Public License (CC-BY 4.0), a copy of which is available at: (https://creativecommons.org/licenses/by/4.0/legalcode). This license permits unrestricted use, distribution, and reproduction in any medium, provided the original author and source are credited. 